\title{
Aportes para una conducción colaborativa del proceso civil chileno: pensando una nueva justicia*
}

\section{Maite Aguirrezabal Grünstein** \\ 1. Álvaro Pérez Ragone***}

RESUMEN. La cultura jurídico-procesal comparada contemporánea comienza a ser consistente en cuanto a la necesidad de un juez cercano y empático en su relación con las partes y sus representantes, lo que requiere una transformación de paradigmas. La instauración del proceso por audiencias, con la mejora de todas las condiciones orgánicas y financieras del sistema de administración de justicia civil, no parece ser suficiente; se requiere además fijar nuevos roles al juez y a las partes. Por el lado del juez, se impone una visión en la que este asume un rol activo, de gerente y conductor. De esta forma se verifica una simbiosis entre los sistemas adversarial e inquisitorio. Por el lado de las partes, la competencia entre estas por obtener un resultado positivo se matiza y equilibra con la cooperación. Todo el engranaje impone conductas de trato equitativo y debido y justo proceso

* Fecha de recepción: I7 de noviembre de 20I7. Fecha de aceptación: I4 de mayo de 2018.

Para citar el artículo: Aguirrezabal Grünstein, M. y Pérez Ragone, Á. "Aportes para una conducción colaborativa del proceso civil chileno: pensando una nueva justicia", Revista de Derecho Privado, Universidad Externado de Colombia, n. ${ }^{\circ}$ 35, julio-diciembre de 2018, 293-326. Dor: https://doi.org/ro.18601/or 234366.n35.I I

El presente trabajo se elabora en el marco de los Proyectos Fondecyt Regular n. ${ }^{\circ}$ i 50276 , titulado "La colaboración procesal como elemento configurador del principio dispositivo en el proceso civil por audiencias", del que la coautora es la investigadora responsable, y n. ${ }^{\circ}$ I 150468 , titulado "Gestión y dirección eficiente de procesos civiles" del que el coautor es investigador responsable.

** Doctora en Derecho por la Universidad de Navarra, España. Profesora investigadora de la Facultad de Derecho de la Universidad de Los Andes, Santiago de Chile, Chile. Contacto: maguirrezabal@uandes.cl

*** Doctor en Derecho por la Universidad de Colonia, Alemania. Profesor investigador de la Facultad de Ciencias Jurídicas de la Universidad Católica del Norte, Antofagasta, Chile. Contacto: alvaro.perezo @@ucn.cl 
como valores internos. Estas son condiciones necesarias para un proceso civil eficaz, racional, justo y eficiente.

Palabras clave: proceso civil, colaboración, conducción del proceso, reforma de la justicia civil en Chile.

\title{
Contributions for a Colaborative Case Management into the Chilean Civil Procedure: Thinking in a New Justice
}

\begin{abstract}
Aвstract. The contemporary comparative procedural culture begins to be consistent in the need for a close judge and with an empathic intervention in the proceeding with the parties and their representatives that generates the need for a paradigm transformation. The administration of justice by hearings with the improvement of all organic and financial conditions does not seem to be sufficient without setting roles for the judge and the parties. On the side of the judge imposes a vision that assumes an active managerial role. In this way a symbiosis between the adversarial and inquisitorial systems is verified, because the cooperation of the parties is also necesary. The competition between the parties for obtaining a positive outcome is qualified and balanced with the cooperation imposed on the active conduct that must be performed by the judge as intrinsic value of procedural justice and fairness as framework for a fair, just, rational and efficient justice.
\end{abstract}

KEYwords: Civil procedure, colaborative case management, civil justice reform in Chile.

Sumario. Introducción. i. Formulación del principio dispositivo en la dogmática procesal civil. II. Legalidad procesal y tutela de derechos. III. La colaboración como principio procesal. iv. Abuso del y en el proceso. A. Luces sobre el abuso procesal. B. Sombras sobre el abuso: prudencia en su determinación v. La conducción cooperativa del proceso. vi. La conducción y cooperación procesal formal en la (postergada) reforma a la justicia civil chilena. A. En la determinación del objeto del proceso. B. En la presentación de la demanda y aporte de información. C. En la regulación de las actitudes del demandado. D. En la audiencia preliminar. E. En los poderes del juez para la conducción formal del proceso. Conclusiones. Referencias.

\section{Introducción}

El acceso a la justicia para una tutela judicial efectiva, como un derecho constitucional, permite que el ejercicio de la acción por parte del justiciable inste al aparato judicial a satisfacer sus necesidades legales. La función de los tribunales 
de justicia ha sido usualmente descrita en Chile como el "poder-deber del Estado que radica preferentemente en los tribunales de justicia para conocer, juzgar y hacer ejecutar lo juzgado" $;$ o bien como "el poder que tienen los tribunales de justicia para resolver, por medio del proceso y con efecto de cosa juzgada, los conflictos de relevancia jurídica en cuya solución les corresponde intervenir"2. Así, el centro de atención tradicional ha sido la resolución de controversias mediante conocimiento, juicio y/o ejecución. Por su lado, una mirada renovada sostiene que la función de los tribunales de justicia excede la de solo conocer y resolver los conflictos 3 , que olvida otros objetivos mayores e inmediatos. Las funciones de la justicia en el Estado democrático de derecho serían, además: (i) tutelar los derechos fundamentales, (ii) tutelar los derechos subjetivos legales, (iii) velar por el imperio de la Constitución, (iv) Conocer y resolver los actos judiciales no contenciosos, y (v) Crear derecho en el caso concreto. La trascendencia constitucional de la tutela de los derechos ha sido considerada en las reformas en materia penal, laboral y de familia, así como en las comunicaciones de la dilatada, anhelada y aún no concretada reforma a la justicia civil chilena4. La finalidad del proceso civil no puede entonces ser reducida solo a la solución de controversias.

Sin mayor reflexión, uno podría sentirse atraído por el punto de vista según el cual los resultados mandan, siendo contingentes los procedimientos; o lo que es lo mismo, solo el mérito cuenta, y con relación a él es posible emitir juicios de justo o injusto. De esta manera se banaliza y hasta elimina la justicia procedimental (procedural fairness) como criterio necesario de equidad, se lo torna oscuro, abstracto y hasta vacío. Esta es, sin duda, una consideración demasiado simplista. Incluso concentrados en el resultado final como única consecuencia relevante, implicaría reducir el sistema de justicia a la sola solución de controversias entre las partes, desconociendo que no son los únicos efectos de la adjudicación y que se imponen costos y beneficios también a la sociedad en general. Si el proceso deviene solo en un instrumento para solucionar disputas, torna irrelevante la calidad de la decisión y la manera como se arribó a ella. Incluso con olvido -como bien señala Taruffo- de que la decisión debe hacerse conforme a derecho5.

I Corte Suprema. Fallo Rol n. ${ }^{\circ} 4.079-2009$.

2 Tribunal Constitucional. Fallo Rol n. ${ }^{\circ}$ 2.865-I 5-INA, Considerando trigesimoquinto, haciendo referencia а Соцомво Campbell, J., La jurisdicción. El acto jurídico procesal y la cosa juzgada en el derecho chileno, Santiago de Chile, Jurídica de Chile, I980.

3 Bordali, A., Cortez, G. y Palomo, D., Proceso civil: el juicio ordinario de mayor cuantía, procedimiento sumario y tutela cautelar, 2. ${ }^{\text {e }}$ ed., Santiago de Chile, Thomson Reuters, 2014, Io.

4 Sobre la importancia de la consideración de la justicia como un valor que va más allá de la sola solución de controversias, cfr. Cerda, C., "Razonamiento judicial, verdad y justicia", Cuadernos de Análisis furídico, Escuela de Derecho, Universidad Diego Portales, I99 I, I I-2 2.

5 Taruffo, M., Uma simple verdade. O juiz e a construção dos fatos, trad. V. de P. Ramos, Madrid, Marcial Pons, 2012, I38 s. 
La jurisdicción, mediante el proceso, persigue prioritariamente la oportuna y adecuada tutela de los derechos cuya protección es requerida. De esta forma no solo se tutelan los derechos resolviéndose las controversias, sino que además se hacen efectivos los beneficios para la sociedad en su conjunto ${ }^{6}$.

Los sujetos con sus distintos intereses, la estrategia y el hecho de la victoria y la derrota hacen del proceso una suerte de juego, tal cual lo veía Calamandrei, que necesita coordinación7. La forma como se dinamiza el proceso por el actuar de los sujetos (partes, terceros y juez) ha sido una preocupación constante, incorporándose bajo el alero del principio de la moralidad procesal, que a su vez se concreta en diversos principios como el de buena fe, el de colaboración o cooperación procesal y el de proscripción del abuso del proceso. Parte de la doctrina ha señalado que el exceso de formalismo en los procesos ha contribuido a alejar o a desligar al proceso de la realidad social que lo circunda ${ }^{8}$, aunque esta función social no debería traducirse en un exceso de poderes del juez, conducido por su pura discrecionalidad, que afecte la igualdad de las partes y la pretensión de certeza jurídica9 9 .

La cultura jurídica que comienza a concebir un juez cercano y con una intervención en el proceso empática con las partes y sus representantes genera una transformación de paradigmas. Ahora bien, la instauración del proceso por audiencias, con la mejora de todas las condiciones orgánicas y financieras, no parece ser suficiente si no se fijan responsabilidades y roles al juez y a las partes. Por el lado del juez se impone una visión en la que este asume un papel activo y de conductor. Es posible sostener que las mayores facultades que se otorgan al juez para la conducción del proceso van acompañadas de una mayor responsabilidad que es compartida con las partes. De esta forma se verifica una simbiosis entre los sistemas adversarial e inquisitorio. Desde el punto de vista de las partes, el obtener un resultado positivo de victoria se matiza y equilibra con la cooperación impuesta para el desarrollo de un proceso leal, justo, racional y eficiente ${ }^{\text {Io }}$.

Este artículo se centra en la conducción y gerenciamiento formal del proceso (más concentrado en lo que tradicionalmente se denomina "dirección procesal” formal, antes que en la material, a la que, por cierto, no evade), a lo que

6 Uzelac, A. (coord.), Goals of Civil Justice and Civil Procedure in Contemporary Judicial Systems, Dortrecht, Springer International, 20 I4, 5-I 2; en el mismo sentido Diakonis, A., Grundfragen der Beweiserhebung von Amts wegen im Zivilprozess, Tübingen, Mohr Siebeck, 2014, I8-27; cfr. Osti, A., Teoria e prassi dell'access to justice', Milano, Giuffré, 20 16, 5-1 2.

7 Calamandrei, P., Il processo come giuoco ( I950), en Opere giuridiche, vol. i, Napoli, Morano, I965, 537 .

8 Cfr. Mitidiero, D., Colaboración en el proceso civil. Presupuestos sociales, lógicos y éticos, $3 \cdot{ }^{\mathrm{a}}$ ed., Sao Paulo, Thompson Reuters, 201 5, 26.

9 Cfr. De Oliveira, A., "Poderes del juez y visión cooperativa del proceso", en Revista Iberoamericana de Derecho Procesal, n. ${ }^{\circ}$, $2004,{ }^{2} 38$.

io Settem, O., Applications of the "Fair Hearing" Norm in ECHR Article 6(I) to Civil Proceedings, Dortrecht, Springer, 2016, I I4-I I 8. 
se suma la cooperación de las partes para la determinación de los derechos que se discuten, la corrección (y en su caso saneamiento) del procedimiento y su adecuada prosecución ${ }^{\mathrm{I}}$.

Chile ha reformado su justicia laboral, de familia y penal, ámbitos diversos donde se introdujo el proceso por audiencias que ha requerido cambios de paradigmas sobre el rol deseable de jueces, partes y abogados. Esto contrasta con la justicia civil, donde aún no se logra salir de una escrituración con delegación exagerada y un juez lejano e invisible, donde todavía se espera que sea reanimada la aletargada reforma. Es en ese contexto que se formula esta propuesta de estudio comparada, la cual no se centra en un derecho positivo, el chileno, sino que más bien hace de él un caso de estudio útil para reformas necesarias en curso en otros países.

Este aporte se compone de seis secciones y una conclusión. En la primera sección se presenta la formulación del principio dispositivo en el proceso civil, con sus distintos componentes (I). Luego, se desarrolla el principio de legalidad procesal y su relación con el proceso y la tutela de los derechos (II). Acto seguido, se incorpora el tratamiento de la cooperación o colaboración procesal como principio (III). A seguir, se alude al abuso en y del proceso (IV), para profundizar a continuación sobre la conducción o gerenciamiento compartido (juez y partes) o colaborativo del proceso, lo que permite hablar de dos principios del proceso (v). Para terminar, se lleva el análisis a la diferida y muy necesaria reforma aún pendiente de la justicia civil chilena (vI).

\section{Formulación del principio dispositivo en la dogmática procesal civil}

El principio dispositivo puede definirse como aquel que en el proceso "atribuye a las partes la tarea de estimular la actividad judicial y aportar los materiales del proceso" " 2 . Por él se reconoce la iniciativa exclusiva para poner en movimiento el aparato jurisdiccional, permitiendo al ciudadano, sobre la base de un criterio de oportunidad y decisión personal, decidir si lleva a la tutela judicial el derecho subjetivo e interés legítimo del que cree ser titular. Palacio lo define como "aquel en cuya virtud se confía a la actividad de las partes tanto el estímulo de la función judicial como la aportación de materiales sobre los que ha de versar la decisión del juez" "3, agregando Oteiza que el principio dispositivo supone "el dominio de la parte sobre el derecho que sustenta su pretensión"I4.

Cfr. Cомоglio, L., "Abuso del processo e garanzie costituzionali”, en Rivista di diritto processuale, 2008, 3 I 9 ss.

I 2 Esparza Leibar, I., El principio del debido proceso, Barcelona, Bosch, I995, 33.

I3 Palacio, L., Derecho procesal civil, Buenos Aires, Abeledo Perrot, I979, 253-254.

I4 Oteiza, E., "El principio de colaboración y los hechos como objeto de la prueba. O 'provare o soccombere'. ¿Es posible plantear un dilema absoluto?”, en Los hechos en el proceso civil, MoreLLo, A. (dir.), Buenos Aires, La Ley, 2003, 83 ss. 
Su vigencia obedece principalmente a la ideología liberal que imperaba en la época de la codificación a finales del siglo xix, que se manifiesta en una desconfianza en los poderes del Estado y considera que el proceso civil sirve principalmente para la discusión de intereses privados. Tradicionalmente este principio, que se explica con la fórmula nemo iudex sine actore ${ }^{15}$, confía a las partes el inicio del proceso civil y la aportación del material probatorio.

El principio dispositivo ha sido también caracterizado en un sentido formal y en otro material ${ }^{16}$.

En la primera de sus manifestaciones, se refiere al manejo del proceso por parte de los interesados como instrumento técnico que garantiza el ejercicio de los derechos. Como bien señala Calamandrei,

... [es] la proyección en el campo procesal de aquella autonomía privada en los límites señalados por la ley, que encuentra su más enérgica afirmación en la tradicional figura del derecho subjetivo y, mientras la legislación substancial reconozca la autonomía, el principio dispositivo debe ser coherentemente mantenido en el proceso civil, como expresión insuprimible del poder reconocido a los particulares de disponer de su propia esfera jurídica ${ }^{17}$.

En su orientación material, el principio dispositivo resulta de mayor aplicación cuando se trata de derechos subjetivos enteramente disponibles, disminuyendo su vigencia cuando se comprometan derechos indisponibles, se afecten derechos de terceros o el interés general, aumentando en dichas hipótesis la relevancia del principio de actuación de oficio y no siendo en estos casos permitido a las partes limitar la actividad jurisdiccional ${ }^{18}$.

Una interpretación en extremo liberal del principio dispositivo podría llevarnos a concluir que las partes son dueñas del proceso y que pueden conducirlo a su arbitrio, olvidando que en él interviene también el órgano jurisdiccional, no solo como el llamado a solucionar el conflicto, sino también como un garante de la adecuada administración de justicia, controlando la actividad de las partes. Por estas razones, el rol del juez ha estado en el centro de un debate que también ha tenido repercusiones en nuestro país. Los contornos originales de esta discusión

I 5 Lo que significa que solo habrá actividad jurisdiccional si hay un actor.

i6 Cappelletti, M., "Social and political aspects of civil procedure: Reforms and trends in Western and Eastern Europe", en Michigan Law Review, 69, I97 I, 847 ss.

i 7 Calamandrei, P., Instituciones de derecho procesal civil, vol. I, Buenos Aires, eJEa. I98 I, 404-405; cfr. Montero Aroca, J., Análisis crítico de la ley de enjuiciamiento civil en su centenario, Madrid, Civitas, I 982, 80, sobre la visión de la antigua LEJ española de un rol pasivo para el juez y concentrado fuertemente en las partes en aquella visión liberal.

i 8 Couture, E., Fundamentos del derecho procesal civil, Buenos Aires, Depalma, I958, i 86. Sería el caso, por ejemplo, de los procesos relativos al estado civil de las personas o los procesos ante los tribunales de familia, e incluso ante los tribunales del trabajo. 
nos remiten al rol del juez en la configuración adversarial o inquisitiva de los procedimientos, o como pretendido elemento diferenciador entre los sistemas procesales del civil law y del common law, cuestiones que en la actualidad parecen prácticamente superadas, sea por la poca validez reconocida a estos esquemas tradicionales de diferenciación o por la tendencia que se ha ido observando hacia la convergencia de los distintos sistemas ${ }^{19}$. Ya en la segunda mitad del siglo pasado, se afirmó la existencia de una tendencia en el proceso civil hacia un rol más activo de los jueces. En la medida en que el juez se involucre en la organización y gerenciamiento del proceso, en el ingreso de la información que aportan las partes y en el esclarecimiento de lo que es o no materia del litigio, será posible tener decisiones mejor construidas ${ }^{2}$. En forma más asertiva puede sostenerse que la eficiencia depende de decisiones sustantivas sobre lo que es la función judicial y el rol que dentro de ella juegan los jueces, los funcionarios judiciales y los litigantes, y que estas definiciones condicionan la gestión judicial y la contribución que de ella puede esperarse. Marcel Storme ${ }^{2}$ consideró la señalada tendencia como inexorable.

\section{Legalidad procesal y tutela de derechos}

Cómo distribuir roles y con ellos responsabilidades entre el tribunal y las partes no es tarea fácil, puesto que para esos efectos la ley suele recurrir a enunciados abiertos con amplios márgenes interpretativos ${ }^{22}$. Primero, el argumento del "principio de legalidad", muchas veces entendido como la imposición de un único tipo de proceso y procedimiento que sería respetuoso de las garantías del debido proceso, resguardando así la legítima confianza y previsibilidad en todos los ciudadanos, corresponde a una mirada insuficiente. La realidad del derecho material y la controversia tienen particularidades que imponen flexibilidad, adecuación de la norma procesal a la realidad material y no a la inversa. Segundo, y en consecuencia, la práctica judicial y las cláusulas abiertas legales podrían sus-

i9 Así Dondi, A., Ansanelli, V. y Comoglio, P., Processo civile in evoluzione, una prospettiva comparata, Milano, Giuffré, 20 I5, IO-I 2; VERKERK, R., "What is judicial case management? A transnational and European perspective", en VAN RheE, C. H. (ed.), Fudicial case Management and Efficiency in Civil Litigation, Antwerp, Intersentia, 2008, 27-55; Zuckerman, A., "The challenge of civil justice reform: Effective court management of litigation", en City University of Hong Kong Law Review, I, 2009, 49-72.

20 Wolf, C. y Zeibig, N., "The judge's case management powers regarding evidence”, en Dimension of Evidence in European Civil Procedure, Rijavec, V., Karestes, T. y TJasa, I. (coords.), Alpen an den Rjin, Kluwer Law International, 2016 , I33-148.

2 I Storme, M., "A single civil procedure for Europe: A cathedral builder's dream”, en Rutsumeikan Law Review, 22, 2005, 87-100.

22 Se pronuncia en este sentido Hunter, I., "Rol y poderes del juez civil: una mirada desde la eficiencia del proceso", en Revista de Derecho de la Universidad Católica del Norte, 20 I I, 73 ss. 
tentar la necesidad de una cierta flexibilidad, justamente para la efectividad de la tutela judicial de acuerdo al derecho que debe protegerse ${ }^{23}$.

Es necesario eludir el falso dilema: eficacia y eficiencia "o" seguridad-rigidez-certeza. Ambas integran un derecho fundamental procesal, que es el justo y racional proceso. El criterio y el examen de proporcionalidad imponen una nueva visión de la tutela judicial requerida y la técnica procesal para alcanzarla ${ }^{24}$. No hay una única forma de impartir justicia con seguridad, eficacia y eficiencia; es a partir del derecho sustantivo que se impone la adecuación de los medios para su tutela ${ }^{25}$. La flexibilidad del proceso es importante, aunque desde las garantías del debido y justo proceso a veces es vista como inconveniente ${ }^{26}$. Ahora bien, esas mismas garantías constitucionales, que a primera vista impondrían una cierta rigidez al proceso, serían consecuencia necesaria de la legalidad en esta visión que debe ser superada; lo que acontece es que finalmente termina afectando los derechos que deben ser tutelados y deviniendo ineficaz ${ }^{27}$.

El pasado siglo xx consolidó la eficiencia y la eficacia de los procesos por audiencias. Ello supera el binomio escrituración y oralidad bajo la idea de que son mutuamente excluyentes. El uso estratégico de la escrituración y la combinación con la oralidad es lo que evidencia condiciones más óptimas para un mejor conocimiento y decisión. Ninguna reforma a la justicia civil se satisface solo con nuevos procesos y procedimientos, requiriéndose además de consideraciones de política pública, planificación, implementación, seguimiento, reformulaciones orgánicas y recursos para la cultura del proceso por audiencias. Se puede constatar una marcada tendencia a entregar cada vez mayores responsabilidades a los jueces y al sistema judicial para asegurar una administración de justicia eficiente,

23 Stürner, R. "Die Rolle des dogmatischen Denkens in Zivilprozessrecht”, en Zeitschrift für Zivilprozess, I39, 20I4, 27 I-297; ver igualmente CADIET, L., Les conflits de légalité procédurale dans le procès civil, libro-homenaje Mélanges Boré, Paris, 2007, 57-78; ZAGreBelsky, G., El derecho dúctil, Madrid, Trotta, I987, I34.

24 Tronson, B. "Towards proportionality. The 'quick, cheap and just' balance in civil litigation", en Picker, C. y Seidman, G. The Dynamism of Civil Procedure. Global Trends and Developments, Dordrecht, Springer International, 2016, I83-202; Carratta, A. y Taruffo, M., Poteri del giudice. Libro primo artt. I I 2-I 20, Bologna, Zanichelli, 20I 5, $250-25^{8}$.

25 Sorabji, J. "Prospects for proportionality", en Civil fustice Quaterly, 32, 2, 20 I3, 2 I3-2 I 8; VoIGT, S. y Bialy, N., "Identifying the determinants of judicial performance. taxpayers' money well spent?", Working Paper 20I302, Hamburg, Institute for Research in Economic and Fiscal Issues, 20I3, disponible en: http://de.irefeurope.org/sites/de.irefeurope.org/IMG/pdf/voigt_ and_el-bialy_20I3_final.pdf [Consultado el i 2 de enero de 20I7].

26 Cfr. Basilico, G., "Il procedimento sommario di cognizione", en Giusto proceso civile, 20 Iо, 737770.

27 Ver el aporte de CADiEt, L., "La legalité procedurale en matiére civile", informe ante la Cout de Cassation, 201 2, 6-ıо, disponible en: https:/www.courdecassation.fr/ıмG/File/intervention_cadiet.pdf [consultado el I3 de enero de 20I7]; cfr. Guinchard, S., en Guinchard, S., Chainais y C., Delicostopoulos et al., Droit processuel, 8. ${ }^{a}$ ed., Paris, Dalloz, 2015 , n. $^{\circ} 225$; Giordano, R., "Procedimento sommario di cognizione", en La riforma del processo civile, Milano, Giuffré, $2014,827-832$. 
económica y justa ${ }^{28}$. Según esto, el paradigma según el cual el único objetivo de los tribunales de justicia es alcanzar la decisión correcta del litigio, sin consideración del tiempo consumido en ello, del costo para los litigantes y el sistema en su conjunto, de la razonabilidad y eficacia de la solución, ha ido quedando atrás. El rol gestor del juez repercute directamente en el acceso a la justicia, el derecho a obtener un resultado motivado y, finalmente, su efectividad, todo en tanto debido y justo proceso ${ }^{29}$. Cierra este círculo el hecho de que la normativa más importante sobre derechos humanos en materia procesal resalta el derecho de los justiciables a un juicio rápido o en un plazo razonable, incluyendo en este concepto la idea de que el juicio justo debe alcanzarse también a un costo razonable. Esto ha forzado a los Estados a implementar procedimientos y mecanismos que permitan a los justiciables obtener la tutela de sus derechos en tiempos acotados, y considerar el procesamiento de los casos y funcionamiento del sistema como un todo ${ }^{3}$.

El problema de la lentitud de la justicia civil exige una solución compleja y multidisciplinaria ${ }^{\mathrm{I}}$. En efecto, en respuesta a las extendidas críticas que se han formulado al funcionamiento de los sistemas de justicia, distintos sectores de la doctrina han volcado su mirada sobre la figura del juez, cuya posición institucional le permite equilibrar los diversos intereses en juego en búsqueda de una mayor eficiencia ${ }^{32}$. La consideración de una adecuada regulación de la conducción y gerenciamiento del proceso, formal y material, para cada caso concreto resulta importante. La conducción de un proceso impone delimitar los marcos de actuación del juez. La incorporación de una consideración macro que pondere la justicia, la equidad, la economía procesal y el impacto de un caso concreto dentro de la totalidad de los casos en curso y los que potencialmente podrían ingresar al sistema judicial. Ello significa incorporar tanto respecto del poder judicial como de sus usuarios la necesidad de ponderar y tratar proporcionalmente cada caso en el contexto de otros ${ }^{33}$.

28 Cfr. Brazdeikis, A., Nekrosius, V., Simaites, R. y Vebraite, V., Ways of Implementation of the Rights to Civil Proceedings within a Reasonable Time, Vilnius, Universidad de Vilnius, 2016, I24I 26.

29 Galligan, D., Due Process and Fair Procedures, Oxford, Oxford University Clarendon Press, I996, IO-25.

30 Cappelletti, M. y Garth, B. "Access to justice: Newest wave in the worldwide movement to make rights effective", en Buffalo Law Review, vol. 27, I978, I8I-292; oEcD, "Giustizia civile: come promuoverne l'efficienza?", en oecd Economics Department Policy Notes, 201 3, n. ${ }^{\circ}$ i 8.

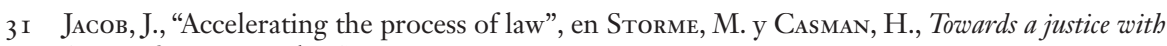
buman face, Dortrecht, Springer, I978, 305-3 Iо.

32 Amrani-Meккi, S., "Analyse économique et temps du procès", en Cohen, D. (dir.), Droit et économie du procès civil, Paris, LGDJ, 2010, 249-268.

33 Bone, R. G., "Who decides? A critical look at procedural discretion", Cardozo Law Review, 28, 2007, I96I-I996. 
Es necesario establecer las bases del procedimiento por audiencias, y determinar un adecuado uso de la oralidad con base en las potencialidades reales orgánicas y humanas del poder judicial. La importancia de la escrituración y las bases de registro de los procesos asume vital importancia. La adecuada introducción de las nuevas tecnologías y la inteligencia artificial son hoy por hoy elementos coadyuvantes irrenunciables y necesarios. La reestructuración del procedimiento en dos momentos esenciales en los casos más complejos, integrados por una primera audiencia de rol preliminar o preparatorio y otra de prueba, impone nuevos principios que deben ser observados por las partes y el juez. El juez es partícipe necesario y no puede delegar su rol en auxiliares. El abogado y las partes que por él resultan representadas asumen un rol que eleva las exigencias de desempeño y respeto a la ética profesional en el marco de otra forma de desempeño profesional ${ }^{34}$. Permitir que las partes procesales puedan arribar a acuerdos que contribuyan a la eficiencia y eficacia del proceso termina siendo un corolario lógico y necesario para estos nuevos paradigmas. Aceptar la posibilidad -en casos de objeto procesal disponible- de que ciertos requerimientos procedimentales de tiempo, lugar y forma puedan surgir de la propuesta de las partes es reconocer el servicio de la autonomía de la voluntad colaborativa e instrumental a una mejor justicia. La combinación de la conducción del proceso con un juez activo y el equilibrio de la cooperación de las partes podrían permitir una flexibilización y adecuación del procedimiento a las necesidades del derecho sustantivo discutido 35 .

\section{La colaboración como principio procesal}

El principio de colaboración coloca al justiciable (y su representante) en un rol de cooperación con el servicio judicial que se traduce principalmente en la conducta procesal a observar por las partes, en virtud de lo cual se sancionan las actuaciones de quienes traicionan el ideal de búsqueda de la verdad en el proceso civil para que produzca los resultados esperados. Las visiones del proceso, individualista (son solo las partes las responsables del impulso y conducción del proceso) y social (por la oficialidad el juez es quien asume el rol protagónico), se superan o se sintetizan con una nueva mirada. Las partes y el juez asumen responsabilidad en la conducción e impulso del proceso, distribuyéndose roles para un resultado que atañe a toda la sociedad. Las partes deben aportar todo el material de sustento de sus peticiones al tribunal, con diligencia, para la ade-

34 Comoglio, L. P., "Tutela differenciata e pari effetività nella giustizia civile”, en Rivista di Diritto Procesualle, 63, 2008, I 509-I 534.

35 Cfr. en este punto Mitidiero, Colaboración en el proceso civil. Presupuestos sociales, lógicos y éticos, cit., 53 ss., que describe los modelos orgánicos de cooperación procesal y la participación de los distintos intervinientes en dicho proceso, distinguiendo los sistemas isonómico, asimétrico y cooperativo. 
cuada prosecución del caso. En modelos de procesos por audiencia tiene así una importancia fundamental la audiencia preparatoria o preliminar, para el primer acercamiento al caso y la planificación del mismo ${ }^{36}$.

$\mathrm{El}$ aporte informativo y probatorio oportuno de las partes para delimitar su pretensión o defensa integra el principio de cooperación, ello como renovada visión del contradictorio para una justa y pronta resolución del caso ${ }^{37}$. Así, además del conocimiento de la contraparte y del juez, permite organizar de mejor manera los pasos sucesivos: (i) se genera el incentivo para las partes de aportar todo lo relevante y necesario tan pronto como sea posible para concentrar y evitar sorpresas y, por ende, alteraciones innecesarias para la tramitación del proceso; (ii) el tribunal puede evaluar y ordenar la alternativa procesal más adecuada en forma temprana y con la mayor información posible. El principio de cooperación no solo comprende la colaboración entre las partes mediante el ejercicio de sus derechos y deberes procesales, sino que además existe un deber impuesto al tribunal para concentrar y conducir de la mejor manera la conducta de las partes.

Como señala De Oliveira, "en la perspectiva judicial, diría que la sentencia final sólo puede resultar del trabajo conjunto de todos los sujetos del proceso" $3^{8}$, destacando cómo la reforma al proceso civil francés instaura como elementos de la cooperación el equilibrio y el diálogo. Además, considerando "la necesidad de establecerse el permanente concurso de las actividades de los sujetos procesales, con amplia colaboración tanto en la pesquisa de los hechos, cuanto en la valorización jurídica de la causa"39; y se concluye que semejante cooperación se justifica cada vez más. En este sentido, “el diálogo judicial y la cooperación se tornan en una auténtica garantía de democratización del proceso, al impedir que el órgano judicial y la aplicación del iura novit curia redunden en un instrumento de opresión y autoritarismo, sirviendo a veces a un mal explicado tecnicismo, con obstrucción a la efectiva y correcta aplicación del derecho y a la justicia del caso"40.

La defensa de una parte no puede basarse en perjudicar el derecho de defensa de la otra o en la inducción a error del órgano jurisdiccional, ni su libertad puede extenderse al extremo de lesionar la buena fe y la ética procesal. Es decir,

36 Косн, R., Mitwirkungsverantwortung im Zivilprozess, Tübingen, Mohr Siebeck, 2013, IO-2 5 ; cfr. Lienhard, A., Die materielle Prozessleitung der Schweizerischen Zivilprozessordnung, Zürich, Dike, 20I3, $2 \mathrm{I}$.

37 Sobre el principio de cooperación y el rol de las partes en el aporte de los hechos y el derecho para una correcta decisión y resolución del proceso, cfr. Goulart Lanes, J. C., Fatos e direito no processo civil cooperativo, São Paulo, Revistas dos Tribunais, 20I4, I 22-I 30.

38 De Oliveira, "Poderes del juez y visión cooperativa del proceso", cit., I39.

39 Ibíd., I 40. Agrega el autor que no obstante la libertad que posea el órgano jurisdiccional para valorar la prueba y la realidad externa al proceso, las partes pueden y deben aportar su cooperación, por no constituir un trabajo exclusivo del órgano jurisdiccional.

40 Ibíd., I46. 
... la colaboración, la buena fe y lealtad procesal, la moralización del proceso y el llamado solidarismo toman la palabra buscando dejar atrás la idea del proceso como una contienda entre partes parciales enfrentadas ante un tercero imparcial, y en el afán de la búsqueda de la verdad objetiva impone la redefinición del principio de la buena fe procesal para dar lugar a un deber de colaboración entre todos los que intervienen en el proceso, incluyendo deberes de asistencia del juez, y los deberes de veracidad e integridad de las partes ${ }^{4}$.

A lo largo de la historia, la relación entre la ética y el derecho procesal ha experimentado importantes cambios. En la actualidad, la óptica individualista de los derechos subjetivos que los concebía como ilimitados y absolutos ha sido morigerada por la noción de bien social que cumplen y por la introducción de la teoría del abuso del derecho, que marca la moralidad en el ejercicio de los derechos. La buena fe es un principio general que rige en todos los ámbitos del derecho. Sin embargo, no existe una definición única de este concepto, debiendo la doctrina definir los elementos que la componen; por lo cual puede exigirse una conducta correcta ${ }^{2}$. En el fondo, "con el principio de buena fe se busca que el proceso sea efectivamente un mecanismo para conseguir la justicia, evitando las posibles inmoralidades de que puedan servirse las partes en el ámbito procesal, para obtener una victoria a toda costa" 43 . Busca conseguir que todos los que participan en una relación procesal ajusten sus actuaciones a las pautas éticas más elementales, reprobando cualquier actuación que configure una utilización dolosa o fraudulenta del proceso.

El deber de colaboración, que constituye una especificación del principio de la lealtad procesal, puede definirse como "el conjunto de reglas de conducta, gobernadas por el imperativo ético, a las cuales deben ajustarse todos los sujetos del proceso", que "proscribe la malicia, la mala fe y la deshonestidad como instrumentos inaceptables para ganar los pleitos" 44 , de manera que la veracidad y la probidad son parte integrante de este deber general. El análisis de la teoría del abuso del derecho tradicionalmente se ha desarrollado como un aspecto de la responsabilidad civil. La finalidad del desarrollo de esta teoría, como señala Condorelli, ha de buscarse en "un sano equilibrio que, sin prohijar la conducta

Picó I Junoy, J., "Il diritto processuale tra garantismo ed efficacia: un dibattito mal impostato", en Studi di diritto processuale civile in onore Giuseppe Tarzia, Milano, Giuffré, 2005, I, 2 I 3 ss.; cfr. Montero, J., Ortells, M. y Gómez-Colomer, J., Derecho jurisdiccional. Parte general, t. i, Barcelona, Bosch, 1993, 465-47I.

42 Ver una introducción a este planteo en Taruffo, M., "General report abuse of procedural rights: Comparative standards of procedural fairness", en Taruffo, M., Abuse of Procedural Rights, The Hague, Kluwer Law International, I999, 3-29.

43 Picó I Junoy, J., El principio de la buena fe procesal, Barcelona, Bosch, 2003, 69.

44 Bustamente, M., "Principios del derecho procesal", en Ramírez, D. M. et al., Derecho procesal contemporáneo, Medellín, Universidad de Medellín, 20 10, 98. 
abusiva, no frustre, en concreto, el ejercicio de la libertad individual en ese mundo tan complejo del proceso y que no desemboque, a la postre, en un ataque de las garantías que establece la Constitución"45. Se incorpora así en definitiva un requisito de diálogo entre las partes y con el tribunal para un empatía que finalmente se manifieste en la correcta prosecución del proceso y un trato equitativo $^{4}$.

En la actualidad se considera que es un tema propio de la teoría general del derecho, aplicable a todo el ámbito jurídico, por considerarse como un postulado general, con aspectos comunes, y otros específicos según la rama a que se refiera. Lo anterior lo hace operativo para todo el ordenamiento jurídico, agregando la doctrina 47 que hoy "se expresa naturalmente en el proceso", porque allí encuentra sus manifestaciones principales, sea en el ejercicio abusivo del derecho subjetivo o en el abuso del proceso propiamente tal ${ }^{4}$. Se ha señalado que en el abuso de los derechos procesales se da siempre un proceder inadecuado, ya sea del ejercicio del derecho de acción, de contradicción, de las potestades jurisdiccionales o de los deberes funcionales del oficio, por lo cual el acto abusivo podrá ser imputado a las partes, a sus defensores o al juez, o a alguno de los intervinientes en el proceso, se trate o no de un auxiliar de la administración de justicia49.

Puede sostenerse que hay abuso procesal en el ejercicio de los actos procesales regulares, válidos y eficaces que conforman el debido proceso, cuando se pretende alterar la finalidad para la cual ha sido previsto o su virtualidad $5^{\circ}$. Ello ya por extralimitar la función del acto o por su mal uso, configurándose "cuando la conducta de cualquiera de los sujetos principales o eventuales que intervienen en el proceso distorsione o desvíe los fines que la ley tuvo en miras al preverla", o bien "cuando exceda los límites que imponen para su realización la buena fe, la moral y las buenas costumbres" $5^{\mathrm{I}}$.

De conformidad con esta posición, un acto es abusivo independientemente de toda intencionalidad dolosa o culpable cuando se desvía del fin que le asigna el ordenamiento al derecho ejercido. Esto supone como único requisito que la exteriorización del acto haya provocado un daño jurídico independiente de

45 Condorelli, E., Del abuso y la mala fe dentro del proceso, Buenos Aires, Abeledo Perrot, i986, i 80.

46 Cfr. los recientes aportes de M. Edge relacionando estos conceptos con el del Estado y sus funciones: Political Philosophy, Empathy and Political fustice, London, Routledge, 20 I6, 41-46.

47 En este sentido, Gelsi Bidart A., "Abuso del proceso", ponencia presentada en el xi Congreso Nacional de Derecho Procesal, La Plata, i 98 i, 2 i r.

48 Cfr. Taruffo, M., "Abuso del processo", en Contratto e impresa, 3 I, 4-5, 20 I 5, 832-846.

49 Peyrano, J., "Abuso de los derechos procesales”, en furisprudencia Santafecina, 34, Santa Fe, r998, 22.

50 Gozaíni, O., Tratado de derecho procesal civil, Buenos Aires, La Ley, 2009, 5 o i; cfr. Gozaíni, O. La conducta en el proceso, Buenos Aires, Platense, I988, 9.

5 I García Solá, M., "De la necesidad de compatibilizar en el proceso el principio del abuso del derecho con la garantía de defensa en juicio", en Abuso procesal, Peyrano, J. (dir.), Buenos Aires, Rubinzal Culzoni, 30. 
la intención o elemento subjetivo ${ }^{52}$. En ordenamientos procesales civiles más modernos que el chileno se contienen, además de una norma general de moralidad del proceso, diversas normas particulares que apuntan a evitar el abuso en momentos determinados y que, de cometerse este, derivan en sanciones de carácter pecuniario. Así, se señaló por la Corte Constitucional colombiana que debe valorarse la naturaleza del proceso, la trascendencia de la falta, las condiciones particulares del responsable y su situación económica, debiendo además considerarse en la imposición de la multa la temeridad o mala fe del responsable y la falta del ejercicio legítimo de un derecho de las partes ${ }^{53}$. Se han propuesto varias clasificaciones del abuso procesal, sea fundado en las consecuencias o bien en quién asume la conducta en un proceso 54.

\section{Abuso del y en el proceso}

El rol del juez y de las partes en el proceso se altera en un modelo de colaboración, puesto que un conflicto que manifiesta intereses antagónicos impide que el proceso se estructure sobre una base colaborativa; es por ello que la ley entra a suplir esta necesidad, estableciendo un deber de colaboración para las partes fundado en la igualdad procesal, así como poderes de conducción para el juez. El modelo colaborativo ${ }^{55}$ plantea un debido proceso leal -por encima de un debido proceso legal-, en el que se efectúa un reconocimiento a la actuación con lealtad

52 En este sentido, cfr. Peyrano, J., “¿Otro principio procesal?: la proscripción del abuso del derecho en el campo del proceso civil”, en Revista el Derecho, I 59, 2009, 925 ss., quien considera que un acto sería abusivo "cuando se desvía del fin que le asigna el ordenamiento siempre y cuando dicha desviación haya causado un daño procesal”.

53 En Sentencia C-7I 3 de 2008.

54 Como complemento se propone distinguir según las consecuencias del acto en: (i) Que la facultad correspondiente no pueda ser ejercitada válidamente o por lo menos, no del modo y con los alcances pretendidos por el abusador; (ii) La aplicación directamente de sanciones por parte del juez; (iii) La declaración de nulidad del acto abusivo, por cuanto el abuso está prohibido y lo que está prohibido en definitiva es nulo; (iv) El resarcimiento de los perjuicios causados, cuando sean solicitados por el afectado, y cuando haya concurrido dolo o culpa del agente. $\mathrm{O}$ bien hacerlo según quién es el titular de la conducta abusiva. Habrá abuso procesal de parte antes de la constitución de la litis mediante la utilización de disposiciones convencionales con consecuencias procesales; o bien habrá abuso técnico procesal cuando la conducta es creación exclusiva del abogado, quien lo realiza en el marco de la amplitud de facultades que le otorga la representación para estar en juicio. Distingue también el abuso de los funcionarios como "burocrático" y que tiene trascendencia en el proceso (así Rambaldo, J., El abuso procesal, Peyrano, J. (dir.), Estudios del proceso civil, Rosario, Rubinzal, I999, 22 I ss.). Taruffo propone una visión muy aceptable sobre la falta de univocidad del concepto y, por ende, sobre la necesidad de criterios para su determinación (TARuffo, ob. cit., nota 43, I 5 ss.); propone distinguir entre casos de abuso del proceso, por el abuso de la litigación o de determinados mecanismos o instrumentos procesales, y hace un detallado desarrollo de criterios para tener en cuenta respecto de cómo regulan los distintos modelos procesales la figura del abuso del proceso.

55 Ver Picó i Junoy, J., “El debido proceso leal. Reflexiones en torno al fundamento constitucional del principio de la buena fe procesal", en Revista Peruana de Derecho Procesal, 2006, 33 I. 
o de buena fe tanto de las partes como del juez, tal como ya lo han hecho numerosas legislaciones comparadas como la francesa ${ }^{5}$ o la española 57.

En este sentido, la consagración de la buena fe como un principio objetivo del proceso civil nos llevaría a las siguientes conclusiones: la prohibición de crear posiciones procesales ilícitas; la prohibición de contravenir los actos propios; la prohibición de abuso en el ejercicio de las facultades procesales, y lo que el autor denomina como la supresión, que la define como la pérdida de una facultad procesal por su no ejercicio en un tiempo suficiente como para que las otras partes puedan presumir que esa facultad ya no será ejercida ${ }^{8}$.

\section{A. Luces sobre el abuso procesal}

Las partes asumen entonces un deber de colaboración con la correcta conducción del proceso. El brocardo de Gayo Male enim nostro jure uti non debemus en la interpretación romano-canónica sustentaba el juramento de no asumir conductas que dilaten el proceso59. Así, los deberes impuestos a las partes comprenden

56 Artículo r6 del nuevo código de procedimiento civil que enuncia: "Le juge doit, en toutes circonstances, faire observer et observer lui-même le principe de la contradiction. Il ne peut retenir, dans sa décision, les moyens, les explications et les documents invoqués ou produits par les parties que si celles-ci ont été à même d'en débattre contradictoirement. Il ne peut fonder sa décision sur les moyens de droit qu'il a relevés d'office sans avoir au préalable invité les parties à présenter leurs observations" ("El juez debe, en todas las circunstancias, hacer observar y observar él mismo el principio de contradicción. No puede retener, en su decisión, los medios, las explicaciones y los documentos invocados o presentados por las partes que sí pudieron debatirlos de manera contradictoria. No puede basar su decisión en los fundamentos jurídicos que ha planteado de oficio sin haber invitado primero a las partes a presentar sus observaciones" (trad. libre).

57 Art. 247 de la Ley de Enjuiciamiento Civil: "I. Los intervinientes en todo tipo de procesos deberán ajustarse en sus actuaciones a las reglas de la buena fe; 2. Los tribunales rechazarán fundadamente las peticiones e incidentes que se formulen con manifiesto abuso de derecho o entrañen fraude de ley o procesal; 3. Si los Tribunales estimaren que alguna de las partes ha actuado conculcando las reglas de la buena fe procesal, podrán imponerle, en pieza separada, mediante acuerdo motivado, y respetando el principio de proporcionalidad, una multa que podrá oscilar de ciento ochenta a seis mil euros, sin que en ningún caso pueda superar la tercera parte de la cuantía del litigio. Para determinar la cuantía de la multa el Tribunal deberá tener en cuenta las circunstancias del hecho de que se trate, así como los perjuicios que al procedimiento o a la otra parte se hubieren podido causar. En todo caso, por el Secretario judicial se hará constar el hecho que motive la actuación correctora, las alegaciones del implicado y el acuerdo que se adopte por el Juez o la Sala; 4. Si los tribunales entendieren que la actuación contraria a las reglas de la buena fe podría ser imputable a alguno de los profesionales intervinientes en el proceso, sin perjuicio de lo dispuesto en el apartado anterior, darán traslado de tal circunstancia a los Colegios profesionales respectivos por si pudiera proceder la imposición de algún tipo de sanción disciplinaria; 5. Las sanciones impuestas al amparo de este artículo se someten al régimen de recursos previstos en el Título v del Libro vir de la Ley Orgánica del Poder Judicial”.

$5^{8}$ Art. $5 \cdot^{\circ}$ del nuevo código procesal civil brasileño: "Aquele que de qualquer forma participa do processo deve comportar-se de acordo com a boa-fe".

59 Caravaglios, A., “'Male enim nostro jure uti non debemus': abuso di diritto o eccesso di potere nell'esercizio di un diritto?”, Reinoso Barbero, F. (dir.), Principios generales del derecho. Antecedentes históricos y borizonte actual, Madrid, Thomson-Aranzadi, 2014, 663 ss. 
también la prohibición del abuso por omisión o comisión que pueda entorpecer la conducción y normal prosecución del proceso ${ }^{60}$. La colaboración con la conducción formal del proceso impone conductas a las partes para evitar que se frustre por negligencia o dolo el acceso a la justicia y el tránsito por ella ${ }^{6 \mathrm{r}}$. Las orientaciones del CEPEJ para la adecuada gestión de los tiempos procesales incluyen también indicaciones para evitar el abuso del proceso ${ }^{62}$.

Las normas sustantivas de derecho definen los derechos y las responsabilidades; las de contratos, por ejemplo, indican cuándo se entiende perfeccionado un tipo de acuerdo así como las facultades y deberes de las partes. También es posible la formulación de normas de procedimiento para guiar las conductas de los intervinientes y arribar a una decisión ${ }^{63}$. El procedimiento proporciona información, especificidad e imparcialidad que requiere el acatamiento del derecho por los ciudadanos, funcionarios y órganos intervinientes ${ }^{64}$. Pero incluso si se respeta ex ante el procedimiento, sus requerimientos de participación, y logra arribarse a una decisión que brinda tutela al derecho invocado, ello debe lidiar con otro riesgo que es el tiempo. Así, entra en juego la condición de oportunidad (justicia retrasada es justicia negada): si los derechos sustantivos son amparados tardíamente hay una privación en el tiempo de su realización. El costo asociado al tiempo de ejercicio de los derechos procesales deviene en una afectación en definitiva de los derechos que se invocan. La impronta de la duración razonable del proceso, a su vez, no es una vía para justificar una rapidez irrazonable para una correcta decisión, ni tampoco para tachar como abusivas dilaciones que son necesarias y razonables ${ }^{6}$.

60 Cadiet, L., "Case management judiciaire et déformalisation de la procédure", en Revue française d'administration publique, École Nationale d'Administration, I25, 2008, I33-I50; cfr. Recommendation No. (84) 5 of the Committee of Ministers of the Council of Europe of 28 February I984 "on the Principles of Civil Procedure Designed to improve the Functioning of Justice", disponible en: https://wcd.coe.int/com.instranet.instraservlet? command=com.instranet.CmdBlobG et \&instranetimage $=603496 \&$ secMode $=\mathrm{I} \&$ Docid $=682030 \&$ Usage $=2$ [consultado el 20 de diciembre de 2016].

6I Cadiet, L. y Tourneau, P., Abus de droit. Répertoire civil, $3 .{ }^{\text {ème }}$ éd., Paris, Dalloz, 2015, I 28, I 29 , I 32 .

62 Commission for the Efficiency of Justice (CePeJ), "Guidelines for Judicial Time Management", CePeJ, 2oI4, I6, disponible en: https://www.coe.int/t/dghl/cooperation/cepej/Delais/ default_ en.asp [consultado el 28 de diciembre de 2016].

63 Klinger, E. y Bierbrauer, G., "How role and framing influence litigants' perception of civil procedure", en Mathis, K. (ed.), European Perspectives on Behavioral Law and Economics, Bern, International Publishing Switzerland, 2015, I 47 ss.

64 Cfr. Galligan, D., Due Process and Fair Procedures, Oxford, Oxford University Clarendon Press, I997, IO-3 I; Doherty, D. y Wolak, J., "When do the ends justify the means? Evaluating procedural fairness", en Political Behavior, 34, 2, 2012, 30I-323.

65 Sobre los excesos en los argumentos y aplicación de la "duración razonable", cfr. VERDE, G., "Il processo sotto l'incubo della ragionevole durata", en Rivista di diritto processuale, 20 I I, 5 I 3. 


\section{B. Sombras sobre el abuso: prudencia en su determinación}

Todo sistema jurídico que supedita la toma de decisiones judiciales a un conjunto de normas preconcebidas tiene que enfrentarse a la tensión entre la formulación normativa del ideal y su aproximación en la realidad con lo decidido. Solo si un sistema jurídico es capaz de superar satisfactoriamente el discurso abstracto del derecho prometido y tutelarlo adecuadamente, el mecanismo jurídico cumple su propósito $^{66}$. Cuando sabemos que el resultado es injusto, la justicia del resultado no puede ser la fuente de su autoridad legítima. La justicia procedimental no solo impone reglas claras de participación, sino además compromisos de reconciliación entre sustancia y procedimiento cuando se incurre en un error en el mérito, pudiendo así ser controlable la calidad de la decisión ${ }^{6}$.

Tanto en lo normativo como en la verificación de los hechos, las condiciones epistémicas para lograr la tutela del derecho sustantivo del caso pueden no ser perfectas, pero son $-\mathrm{y}$ debe exigirse que lo sean- las mejores y posibles logradas que resulten aceptables ${ }^{68}$. Con ello se suma la importancia de la racionalidad de la decisión con los minimos razonables de funtamentación y motivación ${ }^{69}$. Por ello no es suficiente una explicación meramente procedimentalista que se contente solo con permitir la participación como necesaria y suficiente para la legitimidad del procedimiento que incluiría la decisión sin más. Esta requiere de racionalidad en la que el resultado puede ser fundadamente explicado con un estándar de lo razonable $7^{\circ}$. Así, no es posible valorar solo lo decidido (el "después") sin el "antes" procedimental que garantiza la participación, como tampoco, ex post, solo considerar a esta como suficiente para aceptar la decisión. La motivación, así, requiere: (i) los elementos estructurales del discurso que permitan establecer si se cumple o no la justificación racional de validez y corrección; y, (ii) el contenido específico del discurso en el que se explicitan las elecciones realizadas por el juzgador según las expectativas creadas durante el procedimiento y que tiene como destinatario a un auditorio amplio, no solo a los intervinientes ${ }^{71}$.

66 Dedeк, H., "From norms to facts: The realization of rights in Common and Civil Private Law", en McGill Law fournal / Revue de droit de McGill, 56, I, 2010,77 -I I4.

67 Cfr. Uzelac, A. y van Rhee, C. H., "Appeals and other means of recourse against judgements in the context of the effective protetion of civil rights and obligations", en Uzelac, A. y van RheE, C. H., Nobody's Perfect, Antwerp, Intersentia, 20 I4, 3-6.

68 Gentili, A., "Contraddittorio e giusta decisione nel processo civile", en Rivista trimestrale di diritto e procedura civile, 2, 2009, 757-760.

69 Aarnio, A., The Rational as Reasonable. A Treatise on Legal fustification, Netherlands, Springer, I 987 , I0-25.

70 Nimiluoto, I., "Is it rational to be rational?", en Krawietz, W., Summers, R., Weinberger, O. y von Wright, G. H., The Reasonable as Rational?, Berlin, Duncker \& Humblot, 2000, IO I-I IO.

7 I Taruffo, M., La motivazione della sentenza civile, Padova, Cedam, I975, 288. 
Los institutos del proceso dependen de la estructura no solo de las normas que instituyen derechos, sino también de las formas de protección o tutela que el propio derecho sustancial les confiere ${ }^{72}$. Para que las partes puedan intervenir adecuadamente, de forma que sea posible solicitar la efectiva tutela del derecho material, existe la necesidad de un procedimiento abierto a la participación, que sea estructurado de manera idónea. Ello exige del Estado una serie de prestaciones, como la puesta a disposición de procedimientos y técnicas procesales idóneas a las variadas situaciones de derecho sustancial (debida por el legislador); súmase a ello la comprensión, por parte de la jurisdicción, de las normas procesales y de la propia función del proceso, a partir del derecho material y de la situación concreta de conflicto.

La incorporación de límites a la conducta de las partes debe congeniarse con la libertad de actuación estratégica que debe también respetarse. El proceso tiene previstas sanciones para los actos que no satisfagan sus imposiciones, por ello incluso la nulidad procesal tiene particularidades propias que la diferencian de la sustantiva 73 . Desconocer que un proceso judicial es dialéctico y que se concreta en una victoria y una derrota sería ingenuo. Sancionar cualquier conducta de las partes con casos abiertos sin limitaciones o especificaciones que trasciendan las solas aspiraciones morales o de lealtad genéricas limita innecesariamente la libertad e igualdad de las partes. La dificultad radica, pues, en poder discernir cuándo un acto procesal lícito deviene en abusivo ${ }^{74}$. Bien ha señalado Taruffo que en los casos donde se deja margen de discrecionalidad a la parte o sus abogados, en los cuales resulta más difícil determinar el límite, pues la genérica referencia a la "buena fe" o a la "lealtad" no basta75. Más convincente resulta objetar como abusivo todo aquello que obstaculice una adecuada prestación del servicio de justicia, que afecte el trato equitativo en un proceso judicial. Si ello es así, queda mejor incluido dentro de la imposición de justicia procedimental del debido y justo proceso. Ciertamente en muchos casos el "abuso" en y del proceso más bien reviste un rol argumentativo. Es decir, en términos de Gentili ${ }^{6}$, es parte del argumento para que el juez, en la interpretación de un acto, no acepte aplicar una norma que correspondía, para determinar que es otra en la que se subsume el caso concreto de abuso. La especialidad de la regulación de supuestos y conse-

72 Frison-Roche, M.-A., "La procédure de l'effectivité des droits substantiels”, en BenoÎt-Rohmer, F. y Grewe, C. (ed.), Procédure(s) et effectivité des droits, Bruxelles, Nemesis, 2003 , I-I 2.

73 Cfr. Cordopatri, F., L'abuso del proceso, Padova, Cedam, 2000, 59 ss.

74 Cfr. Ferrari, V., "Etica del processo: profili generali", en Etica del processo e doveri delle parti. Atti del Convegno nazionale dell'Associazione italiana del processo civile, Genova, 20-2I settembre 2013, Bologna, Bolonia University Press, 20 I 5, 20-30, sobre la libertad de las partes y la estrategia procesal.

75 Taruffo, M., "Abuso del processo", en Contratto e impresa, vol. 3 I, n. ${ }^{\circ}$ 4-5, 20 I 5, 832-840.

76 Gentili, A., "L'abuso del diritto come argomento", en Il diritto come dicorso, Milano, Giuffré, $2013,456$. 
cuencias especiales de la norma procesal determina la calificación de abusivo de un acto, por lo que no puede hacerse arbitrariamente 77 .

\section{La conducción cooperativa del proceso}

La conducción de los procesos puede verse a lo menos desde tres esferas que van desde lo más general hasta lo más especial y dependiente del caso concreto: (i) Una primera considera el nivel organizativo tanto horizontal como vertical y orgánico, en referencia a la gestión del despacho (oficina judicial), que involucra toda la estructura del órgano judicial, con pautas de distribución de roles; (ii) la obligación de velar por la adecuada prestación jurisdiccional en un proceso que respeta la legalidad procedimental, es decir, la conducción formal del proceso, en relación con la oportunidad y duración; (iii) finalmente, involucra el plano material: instruir y orientar, generar el contradictorio evitando decisiones sorpresivas, dialogando con las partes sobre el mejor y más eficiente cauce de la decisión sobre el mérito. Aquí se incluye especialmente la conducción y orden de los aportes de las partes en alegaciones y prueba.

La combinación de la escrituración con la oralidad mediante los procesos por audiencia facilita la democratización del proceso, hace transparente el diálogo que necesariamente se debe dar en un proceso judicial, y maximiza el tiempo de cada caso con la organización de las audiencias en que se rige por la concentración de los actos procesales ${ }^{7}$. Esta configuración del rol del juez y de sus responsabilidades son consistentes con la tendencia observada en el derecho comparado según la cual los jueces, -por su posición institucional y capacidad de equilibrar los diversos intereses en juego- resultan un racionalizador de los recursos del sistema, procurando alcanzar la decisión más justa, en plazos acotados y con costos razonables. Ello sin que se excluyan los imperativos de mejora a partir de una conducción procesal activa por el juez, combinada con el diálogo con y entre las partes 79 . La consecuencia sería la simplificación y la implementación de alternativas sumarias (ya como simplificación, celeridad o ambas) ${ }^{80}$. Ello no impide que se puedan preestablecer normativamente los supuestos a los que conviene o deba aplicarse el proceso sumario.

Podría resultar contradictorio requerir un juez activo en la dirección formal y material y a la vez instar a la cooperación de las partes, haciendo que aquel

77 Ibíd.

78 Brändl, B., Prozessökonomie im schweizerischen Recht, Bern, Brändli, 2013, I 2-32 .

79 LegG, M. y Higgins, A., "Responding to cost and delay though overriding objectives-successful innovation?”, en Picker, C. y Seidman, G. (coords.), The Dynamism of Civil Procedure. Global Trends and Developments, Dortrecht, Springer International, I 57-I 8 I.

80 Cfr. Cadiet, L., "L'equilibre entre la rigidité et la flexibilité dans le proces", en Lucon, P. y Aprigliano, R. (dirs.), Processo em fornadas, Salvador, Jus Podivm, 20 i 6, 596-600; Carratta, A., La tutela sommaria in Europa, Napoli, Jovene, 201 2, I8-25. 
quede impedido para adecuar el procedimiento al caso concreto ${ }^{8 \mathrm{I}}$. Por otro lado, Buscaglia ha puesto de relieve que diferentes estudios que utilizan el análisis económico del derecho prueban que una de las causas de la poca efectividad de los poderes judiciales a nivel mundial, la inseguridad jurídica y los altos costos de acceso a la justicia civil y penal, está ligada estrechamente a la falta de activismo gerencial de los jueces y secretarios de juzgado que no están en condiciones o dispuestos a aplicar técnicas de manejo de causas ajustadas a la alta complejidad de algunos tipos de $\operatorname{casos}^{82}$.

Zuckerman ha destacado que la tendencia emergente más clara es aquella hacia el control y gerenciamiento judicial del proceso civil, y que tanto los países de common law como los de civil law muestran un cambio hacia la imposición de un control de la litigación civil ${ }^{83}$. Se concluye con razón que las reformas realizadas a fines del siglo xx y en los primeros años del siglo xxi en modelos procesales con diferentes raíces tienen similitudes en lo que al rol del juez y de las partes se refiere ${ }^{84}$. Así, la conducción del proceso en los niveles formales y sustantivos responde a las siguientes preguntas: (i) Qué es lo que determina el modo como el procedimiento necesita ser dirigido; (ii) En qué nivel la dirección del procedimiento debe ser organizada; (iii) Por quién, y (iv) Cómo el procedimiento necesita

8I Sobre el juez activo como conductor del proceso para adecuarlo al derecho que en él se discute como característica común al que tienden modelos continental, mixtos y anglosajón, cfr. SEIDman, G., "The New Comparative Civil Procedure", en Picker, C. y Seidman, G. (coords.), The Dynamism of Civil Procedure. Global Trends and Developments, Dortrecht, Springer International, 2OI6, 20-23; CAPONI, R., "Rigidità e flessibilità del processo civile", en Lucon, P. y Aprigliano, R. (dirs.), Processo em fornadas, Salvador, Jus Podivm, 2016, 823-834; en el mismo sentido, ya antes, da Fonseca Gajardoni, F., Flexibilização procedimental: um novo enfoque para o estudo do procedimento em matéria processual, São Paulo, Atlas, 2008, I I 2-I I 5; incluso la distinción entre modelos procesales del civil law enfrentado con los del common law es cada vez menos válida debido al acercamiento de los modelos procesales: cfr. STürnER, ob. cit., nota 24, 27 I-2 78 .

82 Buscaglia, E., "Reformas judiciales en países en desarrollo: principios y lecciones de la experiencia internacional", en García, J., LetUria, F. y Osorio J. C. (eds.), Reformas al poder judicial: gobierno judicial, Corte Suprema y gestión. Bases jurídicas y de política pública para un debate necesario, Santiago de Chile, Libertad y Desarrollo y Universidad Adolfo Ibáñez, 2007, 29; cfr. Buscaglia, E. y Dakolias, M., "Judicial reform in Latin American courts. The experience in Argentina and Ecuador", World Bank Technical Paper n. ${ }^{\circ}$ 350, Washington D.C., I 996, 24 ss.; Chase también señala que la falta de conducción y gestión judicial es una causa de la ineficiencia en el caso italiano en la década de I980: Снase, O. G., "Civil litigation delay in Italy and the United States", en The American Fournal of Comparative Law, 36, I988, 4I-87.

83 ZuCKerman, ob. cit., nota 20, 50-55.

84 Cfr. el estudio comparado de Koller, C., "Civil justice in Austrian-German tradition", en UzeLAC, A. (coord.), Goals of Civil Fustice and Civil Procedure in Contemporary Fudicial Systems, Dortrecht, Springer, 35-59; en el mismo sentido, VAN RHEE, C., "The development of civil procedural law in Twenty Century Europe: From party autonomy to judicial case management", en fudicial Case Management and Efficiency in Civil Litigation, Antwerp, Intersentia, 2008, I I; SorabJI, J., English Civil fustice after the Woolf and Fackson Reforms: A Critical Analysis, London, Cambridge University Press, 20I4, 76-85; CADIET, L., "Introduction à la notion de bonne administration de la justice en droit privé", en fustice et cassation, 20I3, I 3 ; cfr. CAI, Y., "Case management in China's Civil Justice System”, en Rhee, C. H. y van-Fu, Y. (coords.), Civil Litigation in China and Europe. Essays on the Role of the Fudge and the Parties, Dortrecht, Springer 2014, 39 ss. 
ser dirigido. Cada una de estas cuestiones se corresponde con una posición en un eje teórico entre dos extremos posibles ${ }^{85}$.

Así, la primera cuestión permite determinar si es el contenido o las particularidades del caso lo que impone el procedimiento o viceversa. Cada uno de estos extremos teóricos forma parte de un mismo eje. El primer extremo descansa en un conjunto de reglas que se aplican para cada caso sin consideración a su naturaleza. El otro extremo ajustaría todas las reglas procesales, direcciones y órdenes a la naturaleza del caso. Como no existe ningún marco regulatorio que aplique algunos de sus extremos en la práctica, lo que tampoco es deseable, los sistemas legales se ubican en alguna parte entre estos ${ }^{86}$.

La segunda cuestión define si es el legislador o son el juez y las partes quienes pueden determinar las reglas y direcciones de gobierno de sus disputas particulares. El primer extremo refleja un sistema en el cual el legislador, en el más alto nivel, ha establecido un conjunto detallado de reglas procesales y direcciones que no dejan espacio para influenciar el procedimiento a ningún operador jurídico. El segundo extremo corresponde a un sistema en el cual se permite a los jueces y abogados establecer sus propias reglas, generalmente diseñadas para la específica naturaleza del caso. Claramente estos son dos extremos teóricos y existen muchas posiciones intermedias ${ }^{87}$.

Respecto de la tercera cuestión, esto es, quién es el primer llamado a tomar tales decisiones o a elaborar tales regulaciones: el juez o las partes y sus abogados, el primer extremo de este eje atribuye todos los poderes en un proceso a las partes $^{88}$. El segundo atribuye todos los poderes al juez. Nuevamente, ninguno de estos extremos existe en la práctica y ninguno de ellos es deseable, sino que los sistemas legales se ubican entre ambos ${ }^{89}$. El cuarto y último es el grado mayor o menor de discrecionalidad, reglada o no, con la cual puede actuar el tribunal. Este ámbito genera a su vez las dudas de por quién y cómo puede ser controlada la discrecionalidad judicial ${ }^{\circ}$.

85 Cfr. con otras reformas más recientes en modelos procesales mixtos como el chino: AHL, B., "Retaining judicial professionalism: The new case guiding mechanism of the Supreme People's Court", The China Quarterly, 2 I 7, 20I4, I 2 I ss.; Bu, Y., "Zukunft und Methodenfrage des chinesischen Zivilprozessrechts", en Zeitschrift für Zivilprozess International, I 8, 2013, 405 ss.

86 Bell, E., "Judicial case management", en Fudicial Studies Institute fournal, 2009, 76-1 2 I; cfr. Frodu, S., "The heritage of the Franz Klein reform of Austrian Civil Procedure in I895-I896", en Civil fustice Quaterly, 31, 2012, I ss.

87 Cfr. De la Oliva Santos, A., "Prudencia versus ideología: de nuevo sobre el papel del juez en el proceso civil", en Ius et Praxis, i 8, 20 12, 2, 243-294; cfr. Peysner, J. y Seneviratne, M., The Management of Civil Cases: The Court and Post-Woolf Landscape, Department for Constitutional Affairs, Research Series 9/05, 2005, I-76.

88 LegG, M., Case Management and Complex Litigation, Australia, Federation Press, 20 I I, I 5-25.

89 Legg y Higgins, ob. cit., nota 80, I 57- I60.

90 Sтіскецввоск, B., Inhalt und Grenzen richterlicher Ermessen im Zivilprozess, Köln, Otto Schmidt, 2002, 550-555; cfr. Resnik, J., "Managerial Judges, Jeremy Bentham and the Privatization of 
Por otro lado, las partes asumen también responsabilidad en cooperar o colaborar con la conducción del proceso en sus tres niveles. Ello impone no solo deberes negativos, entendidos como la omisión de conductas que puedan afectar la normal secuencialidad del proceso, sino además deberes positivos de lealtad y buena fe. Esta visión puede ayudar a coordinar los deberes y obligaciones con las cargas procesales, y se funda en el interés mismo que impulsa a cada parte a maximizar los resultados positivos y minimizar los negativos. El deber de colaboración comprende el diálogo entre las partes y con el tribunal, y permite asignar una importancia a la responsabilidad de las partes en la tramitación del proceso con base en los acuerdos procesales que brindan un marco a la autonomía privada de las partes ${ }^{9}{ }^{1}$. Esta visión de co-responsabilidad entre el juez y las partes se evidencia en lo sostenido por lord Woolf (reconociendo la influencia alemana y francesa), principal impulsor de la introducción de un fuerte case management en Inglaterra, quien ha afirmado que su objetivo no era socavar el carácter adversarial del sistema de justicia civil inglés ${ }^{92}$. De este modo, se mantiene la responsabilidad de las partes y los profesionales del derecho para administrar sus casos, pero ahora en un entorno gestionado y regido por los tribunales y por normas que centran los esfuerzos en las cuestiones clave del caso, en lugar de permitir que todos los temas sean considerados. Esta idea de cooperación entre el juez y las partes en el desarrollo del litigio es clave de la reforma procesal, en concordancia con el desarrollo alcanzado en Europa. El entorno de legitimidad y marcos de verdad estratégicos o no, que puedan darse entre un tribunal dialogante y que inste a las partes a participar con incentivos adecuados, es relevante para el éxito de un proceso y, con él, del sistema en la perspectiva de los futuros procesos que ingresarán a él93.

Adjudication", en Walker J. y Chase O. (eds.), Common Law, Civil Law and the Future of Categories, Toronto, LexisNexis Canada, 2010, 205-224; Bone, R., "Who decides? A critical look at procedural discretion", en Cardozo Law Review, 28, 2007, I96I-1996.

9i Legg y Higgins, ob. cit., nota 80, I 57-i62.

92 Como bien refiere Ogus, A., "Some reflections on the Woolf Interim Report", en Fenn, P., Rickman, N. y Vencappa, D., The Impact of the Woolf Reforms on Costs and Delay, Centre for Risk \& Insurance Studies, 2009, I-40.

93 Uzelac, A., "Global developments. Towards harmonisation (and back)", en Uzelac (coord.), Goals of Civil fustice and Civil Procedure in the Contemporary World, New York-London, Springer, 20I4, 2-IO; cfr. igualmente VAN RHEE, C. y UzeLAC, A., "The pursuit of truth in contemporary civil procedure: Revival of accuracy or new balance in favor of effectiveness?”, en VAN RHEE, C. H. y Uzelac, A. (coords.), Truth and Efficiency in Civil Litigation, Cambridge, Intersentia, 20 I 2, 3-I3. 


\section{La conducción y cooperación procesal formal en la (postergada) reforma a la justicia civil chilena}

El proyecto de código procesal civil para Chile (de ahora en más, PCPC) no ha consagrado la colaboración de las partes como un principio general del proceso, pero podemos entenderlo incorporado considerando otros principios que sí se enuncian, tales como la iniciativa, centrada en el principio dispositivo, la igualdad de oportunidades y la buena fe procesal. Hoy existen numerosas normas procesales que se encuentran inspiradas en la teoría del ejercicio abusivo del derecho, sea previniendo la realización de actuaciones abusivas o imponiendo sanciones a dichas actuaciones

De ahí, entonces, que podamos visualizar diversas manifestaciones de colaboración en la etapa de discusión del procedimiento declarativo contemplado en el proyecto.

\section{A. En la determinación del objeto del proceso}

Se ha señalado que un proceso en el que prima el principio dispositivo es aquel en el cual exclusivamente las partes disponen o determinan la forma y el momento en que plantean su litigio, en otras palabras, se trata del objeto sobre el cual "se proyecta la actividad jurisdiccional o procesal: la del juzgador y la de las partes"94, y que se fija principalmente en los escritos de postulación y discusión.

Esto último se traduce en el aforismo ne eat iudex ultra petita partium, que significa que el juez no puede dar a las partes más de lo que piden y que la determinación del objeto del proceso en el ámbito civil corresponde exclusivamente a las partes, sin perjuicio de que el juzgador pueda hacer un ajuste razonable, sin que ello signifique alterar dicho objeto del proceso 95 .

La contradicción entre las partes, derivada del conflicto de intereses, dará origen al debate dentro del proceso, y el objeto de dicho debate se define, precisamente, a partir de los hechos alegados por el actor en su demanda y por el demandado en su contestación. Se señala entonces que la defensa y la contradicción propias del ejercicio del principio dispositivo no permiten variar los términos del litigio, suponiendo la imposibilidad de que las partes puedan posteriormente agregar nuevos elementos, ya que estos delimitan una concreta acción

94 De la Oliva Santos, A., Objeto del proceso y cosa juzgada en el proceso civil, Madrid, Thompson Civitas, 2005, 23. Agrega que, "en términos clásicos, el objeto del proceso es la cosa (en sentido amplio y, a la vez, propio) de la que un proceso trata: la res de qua agitur, la cosa de que se trata, que en los procesos regidos por el denominado principio dispositivo es, a su vez, la res iudicio deducta (la cosa llevada a juicio)".

95 Lo que sucede, por ejemplo, en materia de fijación de pagos por concepto de indemnizaciones. 
con una pretensión específica, no pudiendo luego ser alterados en su esencia, en atención a la prohibición de la mutatio libelli ${ }^{6}$.

Si se varía uno de estos elementos, se introducen cuestiones nuevas que, como se ha señalado por la jurisprudencia, "alteran los términos precisos del litigio, con indudable merma del derecho de defensa de la otra parte, la cual, de haberse alegado oportunamente la cuestión, podría haber redargüido y probado en contra"97.

Siguiendo esta orientación, el artículo 276 del proyecto establece que "[1]as partes no podrán alterar el contenido de la demanda, la contestación y, en su caso, la reconvención", salvo situaciones de excepción, como la contemplada en el artículo 257 a propósito de la modificación de la demanda antes de su contestación ${ }^{9}$, o en otros casos señalados en el mismo artículo 276 , por ejemplo, la alegación de hechos nuevos, sujeta a ciertas restricciones que resguardan la buena fe procesal.

\section{B. En la presentación de la demanda y aporte de información}

Establece el artículo 253 que la demanda deberá contener "[l]a exposición de cada uno de los hechos en que se funde el petitorio, la indicación precisa de los medios de prueba con los cuales se acreditarán sus fundamentos y el derecho en que se apoya", lo que constituye una innovación en relación con la forma en que se establece la causa de pedir en el artículo 254 del código vigente.

Creemos que esta es una de las principales manifestaciones del principio de colaboración en el proyectado proceso civil, puesto que se obliga al actor a acompañar con su demanda "toda la prueba documental de que se intente valer", sin perjuicio de lo dispuesto en el artículo $27^{699]}$. Si no se dispusiera de alguno de esos documentos, deberá reseñar su contenido en la demanda, indicar con precisión el lugar en que se encuentren o la persona que los tuviere, y solicitar las medidas pertinentes para su incorporación al proceso, de conformidad con lo dispuesto en el artículo $309^{[\mathrm{IoO}]}$. El proyecto ha previsto, entonces, como una carga que el actor ofrezca toda su prueba en la demanda.

Señala el artículo 255 que "el actor deberá indicar en la demanda, con precisión, todos los medios de prueba de que se valdrá, incluyendo el nombre, apellidos, profesión u oficio, cédula de identidad, si se supiere, y domicilio de los testigos y de los peritos que presentará a declarar en juicio, solicitando su dili-

96 Entendida como la prohibición de alterar la causa de pedir que fundamenta la pretensión.

97 Tribunal Supremo español. Sentencia de ${ }_{5}$ de junio de 1982.

98 Pero respetando el principio de bilateralidad, ya que la modificación vale como una nueva demanda y el emplazamiento principia con la notificación de la modificación.

99 Sobre la posibilidad de acreditar los hechos nuevos que regula dicho artículo.

ıoo Que regula la exhibición de documentos. 
genciamiento, si correspondiere”; agregando la norma que “[s]eñalará, asimismo, con claridad y precisión, los hechos sobre los cuales recaerán las declaraciones de testigos y peritos e indicará, pormenorizadamente, los que se acreditarán con los restantes medios, de modo que el tribunal pueda ejercer las facultades que le confiere el artículo 292 "Iог.

En este punto, la norma viene a zanjar de modo incuestionable la discusión sobre si es o no obligatorio acompañar, a la lista de testigos, la minuta de puntos de prueba al tenor de la cual deben ser interrogados, fortaleciendo con ello el principio de transparencia del proceso ${ }^{\mathrm{IO} 2}$.

Luego, el artículo 256 fija la sanción a la falta de ofrecimiento oportuno de prueba, disponiendo que "no se podrá ofrecer ni producir prueba alguna fuera de las oportunidades previstas en la ley", con lo que se restringen abiertamente las oportunidades que hoy contempla el procedimiento ordinario para ofrecer y rendir prueba.

\section{En la regulación de las actitudes del demandado}

El proyecto agrava las consecuencias de la no contestación de la demanda, puesto que mantiene los efectos de la contestación ficta, pero imposibilita la rendición de prueba para el rebelde, salvo que se trate de la alegación de hechos nuevos ${ }^{\mathrm{IO} 3}$. Establece también que no será necesario notificar al demandado rebelde las resoluciones que se dicten durante el curso del proceso, las que producirán efectos a su respecto desde que se pronuncien, con excepción de la resolución que cita a las partes a la audiencia preliminar y la sentencia definitiva de primer grado, las que deberán ser notificadas por cédula ${ }^{\mathrm{IO}}$.

Se repite la exigencia establecida a propósito de la demanda, puesto que el artículo 27 I establece que la contestación de la demanda deberá contener la exposición clara y precisa de cada uno de los hechos que configuren las defensas y excepciones que se oponen a la demanda, señalando los medios de prueba per-

Io I Artículo que establece la posibilidad de excluir las pruebas cuando sean manifiestamente impertinentes o inidóneas; tengan por objeto acreditar hechos públicos y notorios; sean excesivas, o hayan sido obtenidas con infracción de garantías fundamentales o declaradas nulas o recaigan sobre hechos no controvertidos.

IO2 Sobre la obligatoriedad de acompañar en nuestro actual proceso civil la minuta de puntos de prueba, cfr. Rodríguez Papic, I., Procedimiento civil. Fuicio ordinario de mayor cuantia, 7. ed., Santiago de Chile, 20 I $_{5}$, I05 ss.

IO3 "Artículo 264. Rebeldía. Cuando el demandado debidamente emplazado no comparezca dentro del plazo correspondiente, el tribunal tendrá por evacuado el trámite de contestación de la demanda y el proceso se seguirá en su rebeldía, por el solo ministerio de la ley. La rebeldía del demandado importará una negación de los hechos afirmados por el actor en su demanda, pero no podrá rendir prueba en juicio, salvo en la forma y condiciones previstas en el artículo 276 ".

IO4 El demandado rebelde podrá comparecer en cualquier estado del proceso, pero respetando lo que se hubiere actuado con antelación. 
tinentes con los cuales se pretende acreditarlos, el derecho en que se fundan y el petitorio formulado con toda claridad y precisión. También se reitera la sanción ya establecida para el actor, porque en la contestación de la demanda el demandado deberá pronunciarse categórica y precisamente sobre la veracidad de los hechos alegados en la demanda y sobre la autenticidad, integridad y validez de los documentos que a ella se hubieren acompañado.

Si así no lo hiciere, se considerará que se trata de un hecho no controvertido y en consecuencia no podrá ser objeto de prueba. El silencio y las respuestas evasivas o ambiguas podrán producir los efectos que hoy produce la confesión tácita, puesto que se faculta al tribunal para considerarlos como prueba cuando los hechos a que se refieren le sean perjudiciales, también se considerará elemento probatorio la admisión de la autenticidad, integridad y validez de los documentos acompañados ${ }^{105}$.

\section{En la audiencia preliminar}

La inasistencia del actor a la audiencia preliminar producirá la caducidad del procedimiento. Igual sanción tendrá la inasistencia del demandado respecto de la reconvención. En el marco de la colaboración procesal ha encontrado un importante desarrollo el sistema de mecanismos alternativos de solución de conflictos, que permite descongestionar el sistema judicial a través de los denominados equivalentes jurisdiccionales que facilitan soluciones consensuadas por las partes. El artículo 29I del proyecto permite que, por razones de economía procesal, las partes soliciten al órgano jurisdiccional que dé por acreditados ciertos hechos, o bien es el juez el que propone dichas convenciones a las partes con base en el material aportado durante el período de discusión.

\section{E. En los poderes del juez para la conducción formal del proceso}

En lo que respecta a los poderes del juez para la conducción del proceso, el proyecto viene a reforzar las facultades contenidas en el actual texto normativo. El artículo $3 .^{\circ}$ del proyecto establece que la dirección del procedimiento corresponde al tribunal, que adoptará de oficio todas las medidas que considere pertinentes para su válido, eficaz y pronto desarrollo, de modo de evitar su paralización y conducirlo sin dilaciones indebidas a la justa solución del conflicto; para luego establecer en los artículos siguientes que el tribunal velará por la igualdad de las partes en el proceso y que, de oficio o a petición de parte, deberá

I05 Agrega la norma que el hecho alegado en la demanda y no controvertido en su contestación será considerado por el juez como efectivamente ocurrido siempre que se trate de un hecho posible y lícito. Por ello, y en virtud del principio de congruencia, el juez debe abstenerse, en el momento de dictar sentencia, de valorar o desestimar un hecho alegado por el demandante y no controvertido por el accionado. 
prevenir, corregir y sancionar, según corresponda, toda acción u omisión que comporte fraude o abuso procesal, colusión, contravención de actos propios u otra conducta ilícita, dilatoria o de cualquier otro modo contraria a la buena fe.

El artículo 7 I le otorga al tribunal atribuciones para proceder a la dirección de la audiencia. De esta forma, el tribunal está llamado a dirigir el debate, disponer la práctica de actuaciones judiciales, exigir el cumplimiento de los actos procesales que correspondieren, velar por el normal desarrollo de la audiencia y moderar la discusión, según la naturaleza de la audiencia respectiva. Podrá impedir que las alegaciones se desvíen hacia aspectos no pertinentes o inadmisibles, pero con la limitación de no coartar el ejercicio del derecho a defensa de las partes.

También podrá limitar razonablemente el tiempo de uso de la palabra a las partes y a quienes debieren intervenir, fijando límites máximos iguales para todos ellos o interrumpiendo a quien hiciere un uso manifiestamente abusivo o impropio de su facultad. En caso de que una parte contara con más de un abogado, el tribunal podrá solicitarle determinar cuál de ellos hará uso de la palabra o la forma en que se alternarán.

El juez, en la conducción de la audiencia (art. 72), puede ordenar: que quienes asistan a la audiencia guarden respeto y silencio mientras no estén autorizados para exponer o deban responder a las preguntas que se les formulen; que no utilicen ningún elemento que pueda perturbar el orden de la audiencia, o adoptar un comportamiento intimidatorio, provocatorio o contrario al decoro, o, en general, incurrir en conductas contrarias a la disciplina judicial. En el ejercicio de las facultades que la ley le asigna, el juez deberá dispensar a los abogados, permanentemente, un trato respetuoso y considerado. También puede ejercer facultades disciplinarias (art. 73) destinadas a castigar las faltas o abusos que se cometieren durante la audiencia, y en general adoptará las medidas necesarias para garantizar su correcto desarrollo. Los asistentes que infringieren sus deberes de comportamiento durante la audiencia podrán ser sancionados. El juez, además de sancionar al infractor, podrá expulsarlo de la sala, salvo en el caso del abogado, quien podrá ser sancionado al finalizar la audiencia. También tiene poder para prevenir y corregir (art. I 26, "Facultades preventivas y correctivas del tribunal") situaciones en las que considere que se produjo un acto anulable de aquellos que admiten convalidación, sin que se haya saneado la nulidad, para lo cual podrá poner el hecho en conocimiento de las partes, a fin de que procedan como creyeren conveniente a sus derechos. El tribunal solo podrá corregir de oficio los errores que observe en la tramitación del juicio y adoptar las medidas que tiendan a evitar nulidades procesales.

\section{Conclusiones}

La cultura jurídico-procesal comparada contemporánea comienza a ser consistente en cuanto a la necesidad de un juez cercano y que interviene en el proceso 
de manera empática con las partes y sus representantes, lo que genera la necesidad de una transformación de paradigmas. Ahora bien, la instauración del proceso por audiencias, con la mejora de todas las condiciones orgánicas y financieras, no parece ser suficiente si no se fijan roles al juez y a las partes. Por el lado del juez, se impone una visión según la cual este asume un rol activo y de conducción. De esta forma se verifica una simbiosis entre los sistemas adversarial e inquisitorio. El espíritu competitivo de las partes por obtener un resultado positivo se matiza y equilibra con la cooperación en la conducción activa del juez. Las conductas exigidas integran parámetros de trato equitativo, debido y justo proceso como valores internos. Estas son condiciones, no las únicas aunque sí relevantes, de un proceso leal, justo, racional y eficiente.

La conducción adecuada del proceso abierta al complemento de la cooperación de las partes aporta a una mejor prosecución y disuade de mejor forma para evitar conductas que (abusivas o no) puedan entorpecer la normal administración de justicia civil. Esto se puede incluir en cláusulas de trato equitativo y debido y justo proceso. De modo que la juridicidad (superior a la simple "legalidad") procesal no opere con conceptos abstractos de contenido poco claro para el actuar libre pero responsable de las partes.

\section{Referencias}

Aarnio, A., The Rational as Reasonable. A Treatise on Legal fustification, Netherlands, Springer, 1987 .

AнL, B., "Retaining judicial professionalism: The new case guiding mechanism of the Supreme People's Court", The China Quarterly, vol. 2 I 7, 2014.

Amrani-Mekкi, S., "Analyse économique et temps du procès", en Cohen, D. (dir.), Droit et économie du procès civil, Paris, LGDJ, $20 \mathrm{IO}$.

Basilico, G., "Il procedimento sommario di cognizione", en Giusto proceso civile, 20 Io.

Bell, E., "Judicial case management", fudicial Studies Institute fournal, 2009.

Bone, R. G., "Who decides? A critical look at procedural discretion", 28 Cardozo Law Review, 2007.

Bordali, A., Cortez, G. y Palomo, D., Proceso civil: el juicio ordinario de mayor cuantía, procedimiento sumario y tutela cautelar, 2. ${ }^{\mathrm{a}}$ ed., Santiago de Chile, Thomson Reuters, 2014 .

Brändl, B., Prozessökonomie im schweizerischen Recht, Bern, Brändli, 2013.

Brazdeikis, A., Nekrosius, V., Simaites, R. y Vebraite, V., Ways of Implementation of the Rights to Civil Proceedings within a Reasonable Time, Vilnius, Universidad de Vilnius, 2OI6, I 24-I 26.

Bu, Y., "Zukunft und Methodenfrage des chinesischen Zivilprozessrechts", en Zeitschrift für Zivilprozess International, n. ${ }^{\circ}$ 18, 2013 . 
Buscaglia, E. y Dakolias, M., "Judicial Reform in Latin American Courts. The experience in Argentina and Ecuador", World Bank Technical Paper n. ${ }^{\circ} 35^{\circ}$, Washington D.C., I 996.

Buscaglia, E., "Reformas judiciales en países en desarrollo: principios y lecciones de la experiencia internacional", en Reformas al poder judicial: gobierno judicial, Corte Suprema y gestión. Bases jurídicas y de política pública para un debate necesario, en García, J. F., Leturia, F. J. y Osorio J., C. (eds.), Santiago de Chile, Libertad y Desarrollo y Universidad Adolfo Ibáñez, 2007.

Bustamente, M., "Principios del derecho procesal", en Ramírez, D. M. et al., Derecho procesal contemporáneo, Medellín, Universidad de Medellín, 2 o Io.

CADiEt, L. Les conflits de légalité procédurale dans le procès civil., libro-homenaje Mélanges Boré, Paris, 2007.

Cadiet, L., "Case management judiciaire et déformalisation de la procédure", en Revue française d'administration publique, École Nationale d'Administration, n. ${ }^{\circ}$ I $25,2008 / \mathrm{I}$.

Cadiet, L., "Introduction à la notion de bonne administration de la justice en droit privé", en fustice et cassation, 2013.

CAdiet, L., "L'equilibre entre la rigidité et la flexibilité dans le proces", en Lucon, P. y Aprigliano, R. (dirs.), Processo em Fornadas, Salvador, Jus Podivm, 20 i6.

Cadiet, L., "La legalité procedurale en matiére civile", informe ante la Cout de Cassation, 2OI 2, disponible en: https://www.courdecassation.fr/IMG/File/intervention_cadiet.pdf [consultado el I 3 de enero de 201 7 ].

Cadiet, L., Tourneau, P., Abus de droit. Répertoire civil, 3. . ed., Paris, Dalloz, 2015.

CaI, Y., "Case management in China's civil justice system", en RheE, C. H. y van-Fu, Y. (coords.), Civil Litigation in China and Europe. Essays on the Role of the Fudge and the Parties, Dortrecht, Springer 20I4.

Calamandrei, P., Il processo come giuoco (I950), en Opere giuridiche, vol. I, Nápoles, Morano, 1965 .

Calamandrei, P., Instituciones de derecho procesal civil, vol. I, Buenos Aires, EJEA, I98 I.

Caponi, R., "Rigidità e flessibilità del processo civile", en Lucon, P., Aprigliano y R. (dirs.), Processo em fornadas, Salvador, Jus Podivm, 20 I6.

Cappelletti, M. y Garth, B., "Access to justice: Newest wave in the worldwide movement to make rights effective", en Buffalo Law Review, vol. 27, 1978.

Cappelletti, M., "Social and political aspects of civil procedure: Reforms and trends in Western and Eastern Europe", Michigan Law Review, 69, I97 I.

Caravaglios, A., “'Male enim nostro jure uti non debemus': abuso di diritto o eccesso di potere nell'esercizio di un diritto?", en Principios generales del derecho. Antecedentes históricos y borizonte actual, Reinoso, B. F. (dir.), Madrid, Thomson-Aranzadi, 20I4, 663 ss.

Carratta, A. y Taruffo, M., Poteri del giudice. Libro primo artt. i I2-I 2o, Bologna, Zanichelli, 2OI 5 .

Carratta, A., La tutela sommaria in Europa, Napoli, Jovene, 20 I 2. 
Cerda, C., Razonamiento judicial, verdad y justicia, Cuaderno de Análisis Jurídico, Escuela de Derecho, Universidad Diego Portales, I99I, I I-22.

Chase, O. G., "Civil litigation delay in Italy and the United States", en The American Journal of Comparative Law, 36 , 1988.

Commission for the Efficiency of Justice (CePeJ), "Guidelines for Judicial Time Management”, CePeJ, 20r4, disponible en: https://www.coe.int/t/dghl/cooperation/cepej/ Delais/ default_en.asp. [consultado el 28 de diciembre de 20I6].

Comogrio, L. P., "Abuso del processo e garanzie costituzionali", en Rivista di diritto processuale, 2008.

Comoglio, L. P., “Tutela differenziata e pari effettività nella giustizia civile”, en Rivista di diritto procesuale, 2008.

Condorelli, E., Del abuso y la mala fe dentro del proceso, Buenos Aires, Abeledo Perrot, I986.

Cordopatri, F., L'abuso del processo, Padova, Cedam, 2000.

Couture, E., Fundamentos del derecho procesal civil, Buenos Aires, Depalma, $195^{8}$.

Da Fonseca Gajardoni, F., Flexibilização procedimental: um novo enfoque para o estudo do procedimento em matéria processual, São Paulo, Atlas, 2008.

De la Oliva Santos, A., "Prudencia versus ideología: 'De nuevo sobre el papel del juez en el proceso civil'”, en Ius et Praxis, I 8, 201 2, 2.

De la Oliva Santos, A., Objeto del proceso y cosa juzgada en el proceso civil, Madrid, Thompson Civitas, 2005.

De Oliveira, A., "Poderes del juez y visión cooperativa del proceso", en Revista Iberoamericana de Derecho Procesal, n. ${ }^{\circ}$ 4, 2004.

Dedek, H., "From norms to facts: The Realization of rights in Common and Civil Private Law", McGill Law fournal / Revue de droit de McGill, vol. 56, n. ${ }^{\circ}$ I, 20 го.

Diakonis, A., Grundfragen der Beweiserbebung von Amts wegen im Zivilprozess. Tübingen, Mohr Siebeck, 2014, I 8-27.

Doherty, D. y Wolak, J., "When do the ends justify the means? Evaluating procedural fairness", en Political Behavior, vol. 34, n. ${ }^{\circ}$, junio, 2012.

Dondi, A., Ansanelli, V. y Comoglio, P., Processo civile in evoluzione, una prospettiva comparata, Milano, Guiffré, 2015.

Edge, M., Political Philosophy, Empathy and Political fustice, London, Routledge, 2016.

Esparza Leibar, I., El principio del debido proceso, Barcelona, Bosch, I995.

Ferrari, V., "Etica del processo: profili generali", en Etica del processo e doveri delle parti. Atti del Convegno nazionale dell'Associazione italiana del processo civile, Genova, 20-2I settembre 2013, Bolonia, Bolonia University, 2015.

Frison-Roche, M., "La procédure de l'effectivité des droits substantiels", en BenoîTRohmer, F. y Grewe, C. (eds.), "Procédure(s) et effectivité des droits", Bruxelles, Nemesis, 2003. 
Frodu, S., "The heritage of the Franz Klein reform of Austrian Civil Procedure in I895I896", en Civil Fustice Quaterly, 3 I, 2012.

Galligan, D., Due Process and Fair Procedures, Oxford, Oxford University Clarendon Press, 1996.

García Solá, M., "De la necesidad de compatibilizar en el proceso el principio del abuso del derecho con la garantía de defensa en juicio", en Abuso procesal, Peyrano, J. (dir.), Buenos Aires, Rubinzal-Culzoni.

Gelsi Bidart, A., "Abuso del proceso”, ponencia en el xi Congreso Nacional de Derecho Procesal, La Plata, I98I.

Gentili, A., "Contraddittorio e giusta decisione nel processo civile", Rivista trimestrale di diritto e procedura civile, $\mathrm{n}^{\circ}$ 2, 2009.

Gentili, A., "L'abuso del diritto come argomento", en Il diritto come discorso, Milano, Giuffré, 2013.

Giordano, R., "Procedimento sommario di cognizione", en La riforma del processo civile, Milano, Giuffré, 2014.

Goulart Lanes, J. C., Fatos e direito no processo civil cooperativo, São Paulo, Revistas dos Tribunais, 2014 .

Gozaíni, O., La conducta en el proceso, Buenos Aires, Platense, I 988.

Gozaíni, O., Tratado de derecho procesal civil, Buenos Aires, La Ley, 2009.

Guinchard, S., en Guinchard, S., Chainais y C. Delicostopoulos et al., Droit processuel, 8. ${ }^{\mathrm{a}}$ ed., Paris, Dalloz, 2015.

Hunter, I., "Rol y poderes del juez civil: una mirada desde la eficiencia del proceso", Revista de Derecho de la Universidad Católica del Norte, 20 I I.

Jасов, Sir J., "Accelerating the process of law", en Storme, M. y Casman, H., Towards a fustice with human face, Dortrecht, Springer, 1978.

Klinger, E. y Bierbrauer, G., "How role and framing influence litigants' perception of civil procedure", en Mathis, K. (ed.), European Perspectives on Behavioural Law and Economics, Bern, International Publishing Switzerland, 2015.

Косн, R., Mitwirkungsverantwortung im Zivilprozess, Tübingen, Mohr Siebeck, 2013.

Koller, C. "Civil justice in Austrian-German tradition", en Uzelac, A. (coord.), Goals of Civil fustice and Civil Procedure in Contemporary Fudicial Systems, Dortrecht, Springer International.

Legg, M. y Higgins, A., "Responding to cost and delay though overriding objectivessuccessful innovation?”, en Picker, C. y Seidman, G. (coord.), The Dynamism of Civil Procedure. Global Trends and Developments, Dortrecht, Springer International Publishing.

LegG, M., Case Management and Complex Litigation, Australia, Federation Press, 20 I I.

Lienhard, A., Die materielle Prozessleitung der Schweizerischen Zivilprozessordnung, Zürich, Dike, 2013, 2 I.

Mitidiero, D., Colaboración en el proceso civil. Presupuestos sociales, lógicos y éticos, $3 \cdot{ }^{a}$ ed., Sao Paulo, Thompson Reuters, 2015. 
Montero Aroca, J., Análisis crítico de la ley de enjuiciamiento civil en su centenario, Madrid, Civitas, 1982.

Montero, J., Ortells, M. y Gómez-Colomer, J. Derecho jurisdiccional. Parte general, t. I, Barcelona, Bosch, I993.

Ninniluoto, I., "Is it rational to be rational?", en Krawietz, W., Summers, R., Weinberger, O. y von Wright, G. H., The Reasonable as Rational?, Berlin, Duncker \& Humblot, 2000 .

oEcD, Giustizia civile: come promuoverne l'efficienza?, en OECD Economics Department Policy Notes, 20 I3 $_{3}$, No. I 8.

Ogus, A., "Some Reflections on the Woolf Interim Report", en Fenn, P., Rickman, N. y Vencappa, D., The Impact of the Woolf Reforms on Costs and Delay, Centre for Risk \& Insurance Studies, 2009, I-40.

Osti, A. Teoria e prassi dell' 'access to justice', Milano, Giuffré, 20 I6.

Oteiza, E., "El principio de colaboración y los hechos como objeto de la prueba. O 'provare o soccombere'. ¿Es posible plantear un dilema absoluto?”, en Los hechos en el proceso civil, Morello, A. (dir.), Buenos Aires, La Ley, 2003.

Palacio, L., Derecho procesal civil, Buenos Aires, Abeledo Perrot, I979.

Peyrano, J., “¿Otro principio procesal?: la proscripción del abuso del derecho en el campo del proceso civil", en Revista el Derecho, I 59, 2009.

Peyrano, J., "Abuso de los derechos procesales", en Furisprudencia Santafecina, n. ${ }^{\circ}$ 34, I 998.

Peysner, J. y Seneviratne, M., "The Management of Civil Cases: The Court and PostWoolf Lanscape", Department for Constitucional Affairs, Research Series 9/05, 2005 .

Picó I Junoy, J., "El debido proceso leal. Reflexiones en torno al fundamento constitucional del principio de la buena fe procesal", en Revista Peruana de Derecho Procesal, 2006.

Picó I Junoy, J., "Il diritto processuale tra garantismo ed efficacia: un dibattito mal impostato", en Studi di diritto processuale civile in onore Giuseppe Tarzia, I, Milano, Giuffré, 2005 .

Rambaldo, J., "El abuso procesal”, en Peyrano, J. (dir.), Estudios del proceso civil, Rosario, Rubinzal, I999.

Recommendation n. ${ }^{\circ}$ (84) 5 of the Committee of Ministers of the Council of Europe of 28 February 1984 "on the Principles of Civil Procedure Designed to improve the Functioning of Justice", disponible en: https://wcd.coe.int/com.instranet. instraservlet? command $=$ com.instranet. $\mathrm{CmdBlobG}$ et\&instranetimage $=603496 \& \mathrm{sec}$ Mode $=\mathrm{I} \&$ Docid $=682030 \&$ Usage $=2$ [consultado el 20 de diciembre de 2016].

Resnik, J., "Managerial judges, Jeremy Bentham and the privatization of adjudication", en Walker J. y Chase, O. (eds.), Common Law, Civil Law and the Future of Categories, Toronto, LexisNexis Canada, 2010.

Rodríguez Papic, I., Procedimiento civil. Fuicio ordinario de mayor cuantía, 7. ${ }^{\mathrm{a}}$ ed., Santiago de Chile, 2015. 
Seidman, G., "The new comparative civil procedure", en Picker, C. y Seidman, G. (coords.), The Dynamism of Civil Procedure. Global Trends and Developments, Dortrecht, Springer International, 2016.

Settem, O., Applications of the "Fair Hearing" Norm in ECHR Article 6(I) to Civil Proceedings, Dortrecht, Springer International, 2016.

Sorabji, J., "Prospects for proportionality", en Civil Fustice Quaterly, 32, 2, 2013.

Soraвji, J., English Civil fustice after the Woolf and Fackson Reforms: A Critical Analysis, London, Cambridge University Press, 2014.

Stickelbrock, B., Inhalt und Grenzen richterlicher Ermessen im Zivilprozess, Köln, Otto Schmidt, 2002.

Storme, M., "A Single Civil Procedure for Europe: A Cathedral Builder's Dream”, en Rutsumeikan Law Review, 22, 2005.

Stürner, R., "Die Rolle des dogmatischen Denkens in Zivilprozessrecht", en Zeitschrift für Zivilprozess, I39, 2014 .

TARuffo, M., "Abuso del processo", en Contratto e impresa, vol. 3 I, n. ${ }^{4-5}$, 20 I 5.

TARuffo, M., "General report abuse of procedural rights: Comparative standards of procedural fairness", en TAruffo, M., Abuse of Procedural Rights, The Hague, Kluwer Law International, I999.

TARuffo, M., La motivazione della sentenza civile, Padova, Cedam, I975.

TAruffo, M., Uma simples verdade. O juiz e a construção dos fatos, trad. V. de P. Ramos, Madrid, Marcial Pons, 2012.

Tronson, B., "Towards proportionality. The 'quick, cheap and just' balance in civil litigation”, en Picker, C. y Seidman, G., The Dynamism of Civil Procedure. Global Trends and Developments, Dortrecht, Springer International, 2016.

Uzelac, A. y van Rhee, C. H., "Appeals and other means of recourse against judgements in the context of the effective protetion of civil rights and obligations", en UzELAC, A. y van Rhee, C. H., Nobody's Perfect, Antwerp, Intersentia, 2014.

Uzelac, A., "Global developments. Towards harmonisation (and back)", en Uzelac, A. (coord.), Goals of Civil Fustice and Civil Procedure in the Contemporary World, New York-London, Springer 20I4.

Uzelac, A., "Goals of civil justice and civil procedure in contemporary judicial systems", Uzelac, A. (coord.), Goals of Civil Fustice and Civil Procedure in Contemporary Fudicial Systems, Dortrecht, Springer International, 20I4.

VAn Rhee, C. y Uzelac, A., "The pursuit of truth in contemporary civil procedure: Revival of accuracy or new balance in favor of effectiveness?", en van RHEE, C. H. y UzELAC, A. (coords.), Truth and Efficiency in Civil Litigation, Cambridge, Intersentia, $20 \mathrm{I} 2$.

VAn Rhee, C., "The development of civil procedural law in Twenty Century Europe: From party autonomy to judicial case management", en Fudicial Case Management and Efficiency in Civil Litigation, Antwerp, Intersentia, 2008.

Verde, G., "Il processo sotto l'incubo della ragionevole durata", en Rivista di diritto processuale, $20 \mathrm{I}$ I. 
Verkerk, R., "What is judicial case management? A transnational and European perspective", en Fudicial Case Management and Efficiency in Civil Litigation, van Rhee C. H. (ed.), Intersentia, Antwerp, 2008.

Voigt, S. y Bialy, N., "Identifying the Determinants of Judicial Performance. Taxpayers' Money Well Spent?”, Working Paper 201302, Hamburg, Institut for Research in Economic and Fiscal Issues, 20I3, disponible en: http://de.irefeurope.org/sITEs/ de.irefeurope.org/IMG/pdf/voigt_and_el-bialy_20I3_final.pdf [consultado el I 2 de enero de 2017$]$.

Wolf, C. y Zeibig, N., "The judge's case management powers regarding evidence", en Dimension of Evidence in European Civil Procedure, Rijavec, V., Karestes, T. y TJasa, I. (coords.), Alpen an den Rjin, Kluwer Law International, 20I6, I33-I48.

Zagrebelsky, G., El derecho dúctil, Madrid, Trotta, I987.

Zuckerman, A., "The challenge of civil justice reform: Effective court management of litigation", en City University of Hong Kong Law Review, I, 2009. 